Portland State University

PDXScholar

$5-15-1981$

\title{
Advanced Decorative Ceramics Techniques for High School Students
}

Deborah Ann Kent

Portland State University

Follow this and additional works at: https://pdxscholar.library.pdx.edu/open_access_etds

Digitart of the Art Education Commons, and the Ceramic Arts Commons Comeners know how access to this document benefits you. Network

Logo

Recommended Citation

Kent, Deborah Ann, "Advanced Decorative Ceramics Techniques for High School Students" (1981). Dissertations and Theses. Paper 3073.

https://doi.org/10.15760/etd.3064

This Thesis is brought to you for free and open access. It has been accepted for inclusion in Dissertations and Theses by an authorized administrator of PDXScholar. Please contact us if we can make this document more accessible: pdxscholar@pdx.edu. 
AN ABSTRACT OF THE THESIS OF Deborah Ann Kent for the Master of Science in Teaching in Art presented May 15, 1981.

Title: Advanced Decorative Ceramics Techniques for High School Students. APPROVED BY MEMBERS OF THE THESIS COMMITTEE:

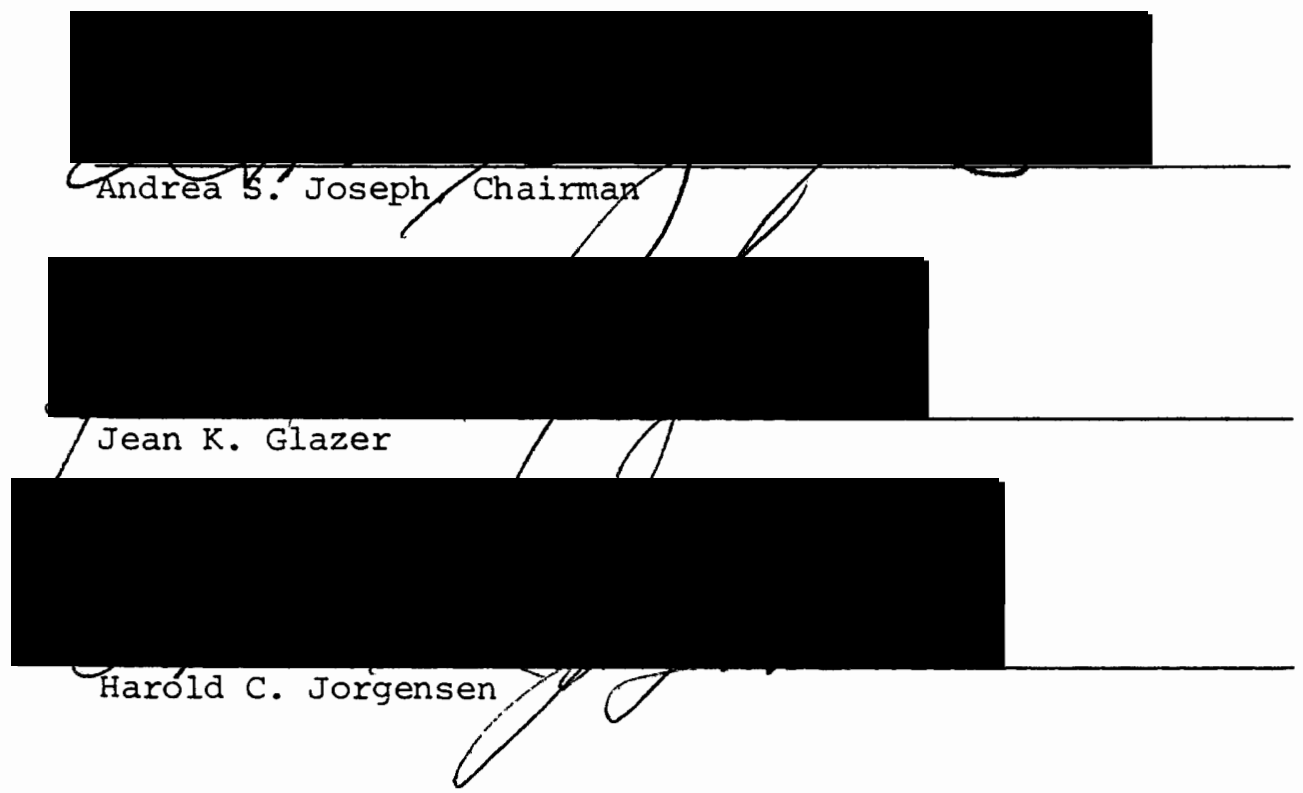

This thesis deals with the implementation of luster and underglaze ceramic decorating techniques into the secondary ceramic curriculum. The formation and presentation of this unit is based upon historical and contemporary research of lusters and underglazes, as well as the author's own work with the materials. An instructional unit was designed to fulfill three primary objectives. First, to acquaint the student with the basic materials and techniques; second, to introduce the student to the conceptualization of successful imagery; third, to give the student ample opportunity to explore the uses and possibilities of the 
materials.

The unit was organized into five assignments. Some limitations were placed on each of the assignments in order to discourage the possibility of frustration. These limitations were broad enough, though, to allow students plenty of creative freedom.

The first assignment was to design and create underglaze imagery on a 6" tile that commemorated or documented an event, person, place, or thing. The objectives of the first assignment were to allow the student to become familiar with the materials and techniques involved in underglazing, as well as being able to demonstrate their uses correctly.

The second assignment was to design and construct a ceramic piece, no taller than 7", with narrative, underglaze imagery. The objectives of the second assignment were to have the student create a successful three-dimensional ceramic underglaze design, as well as gaining skill in the use of the materials.

The third assignment was to create a striped design for a 3 " tile and to apply the design with lusters. The objectives for the third assignment were to allow the student to become familiar with the materials and techniques involved in luster application, as well as being able to demonstrate their uses correctly.

The fourth assignment was to design and create a ceramic piece, no taller than 5", with a patterned luster design. The objectives of the fourth assignment were to have the student create a successful three-dimensional ceramic luster design, as well as gaining skill in the use of the materials. 
The fifth assignment was to design and create a 6" tile with Pacific Northwest imagery, using lusters and underglazes. This tile would become part of a plaque donated to the school. The objective of this assignment was to have the student create imagery which was a successful blend of underglazes and lusters that complemented each other, as well as the format upon which they were applied.

The response to this unit was generally favorable, and the results it produced were generally successful. The first assignment produced a large variety of work with many successful results. Assignment two was the least successful of the five. The creation of three-dimensional narrative designs proved too difficult for the students. Assignment three was very successful. The design qualities of the majority of the striped tiles were extremely successfui. Assignment four produced many successful results and a wide variety of patterns. The results from assignment five were the most successful. As well as the majority of the work being of high quality, the students all displayed a high interest level.

The author of this thesis would recommend the incorporation of a surface decoration unit using lusters and underglazes into a secondary ceramic curriculum. To present this unit successfully, the instructor should be totally familiar with the techniques of luster and underglaze application, and the proper equipment and materials should be available. 
ADVANCED DECORATIVE CERAMICS TECHNIQUES

FOR HIGH SCHOOL STUDENTS

by

DEBORAH ANN KENT

A thesis submitted in partial fulfillment of the requirements for the degree of

\author{
MASTER OF SCIENCE \\ in \\ TEACHING \\ in \\ ART
}

Portland State University 
TO THE OFFICE OF GRADUATE STUDIES AND RESEARCH:

The members of the Committee approve the thesis of

Deborah Ann Kent presented May 15, 1981.

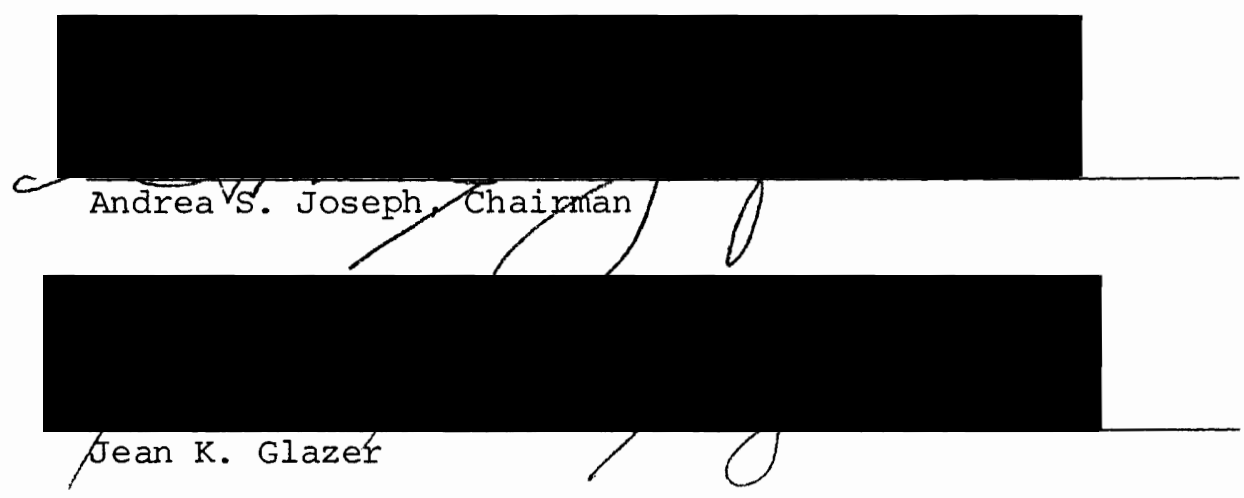

APPROVED :

Garold C. Jorgensep

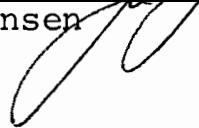

Leonard B. Kimbrell, Head, Department of Art

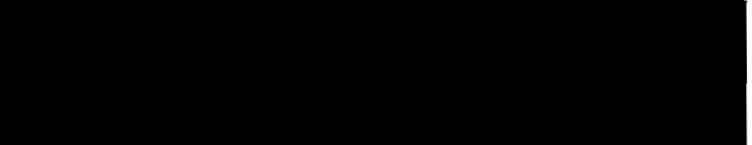

Stanley E. Rauch, Dean of Graduate Studies and Research 
TABLE OF CONTENTS

PAGE

LIST OF FIGURES

$\mathrm{V}$

CHAPTER

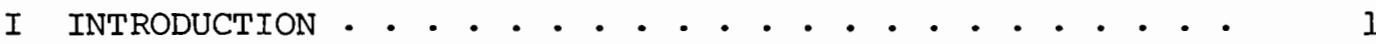

History of Lusters . . . . . . . . . . . . . 2

Various Luster Techniques . . . . . . . . . 16

History of Underglazes . . . . . . . . . . . 26

Various Underglaze Application Methods . . . . . . 41

II ESTABLISHING AN APPROACH TO THE DESIGN OF THE

INSTRUCTIONAL UNIT . . . . . . . . . . . . . 47

Project one . . . . . . . . . . . . . . 49

Project Two . . . . . . . . . . . . . 49

Project Three . . . . . . . . . . . . 50

Project Four . . . . . . . . . . . . . 50

Project Five .. . . . . . . . . . . . 50

III EQUIPMENT NECESSARY FOR THE PROBLEM'S SOLUTION • • • • 52

IV ASSIGNMENTS AND TEACHING METHODS . . . . . . . . . . 58

Assignment one .. . . . . . . . . . 58

Assignment Two . . . . . . . . . . . . 60

Assignment Three .............. 61

Assignment Four . . . . . . . . . . . 62

Assignment Five .. . . . . . . . . . . 63

V EVALUATION AND RECOMMENDATIONS . . . . . . . . . 65 
WORK BY THE STUDENTS

APPENDIX . . . . . . . . . . . . . . . . . . . . 
IIST OF FIGURES

PAGE

FIGURE

1. Islamic Luster Bowl . . . . . . . . . . . . . . 8

2. Vincennes Porcelain Tureen . . . . . . . . . . . 8

3. "Container With Lid", by Eric Gronborg . . . . . . . . 15

4. "Admiral Bird as a Ball and Socket Joint Pondering a Square Ice Whole", by Fred Bauer . . . . . . . . . 15

5. "Car Kiln", by Patti Warashina . . . . . . . . . 15

6. Egyptian Pre Dynastic Vase . . . . . . . . . . . 28

7. Greek Amphora . . . . . . . . . . . . . . . 28

8. Yuan Dynasty Porcelain Stem-Cup . . . . . . . . . . . 34

9. Rookwood Pottery Vases . . . . . . . . . . . . 34

10. "The Other Side of the Coin", by Ed Blackburn . . . . . . . 40

11. "Funk Plate", by Verne Funk . . . . . . . . . . . . . . . . 40

Work by The Students . . . . . . . . . . . . . . 70

12. . . . . . . . . . . . . . . . . . . . 71

13. . . . . . . . . . . . . . . . . . . 71

14. . . . . . . . . . . . . . . . . . . . 72

15. . . . . . . . . . . . . . . . . . . . 72

16. . . . . . . . . . . . . . . . . . . . . 73

17. •. . . . . . . . . . . . . . . . . . . . 73

18. • . . . . . . . . . . . . . . . . . . . . 74

19. •. . . . . . . . . . . . . . . . . . . . . . 74

20. •. • . . . . . . . . . . . . . . . . . . . . 75 
21.

23.

24.

25.

27.

28.

31. 
CHAPTER I

INTRODUCTION

Pottery is an area of art which interests most secondary students. Attracted to clay because of its plastic qualities, students become intrigued with clay's endless possibilities. They are able to work on various technical levels from the construction of basic simple shapes to the exploration of more technical forms. Secondary students have difficulty conceptualizing ideas. They tend to be more responsive to a more visual experience. The use of lusters and underglazes can provide a vehicle for investigation into decorative ceramic design.

The goal of this thesis is to design an instructional unit into a secondary advanced art curriculum where students can learn ceramic surface design through directed experiences with these materials. The results will be documented and evaluated for future use in a similar setting.

The formation of this instructional unit is based on historical and contemporary research of both lusters and underglazes as well as their applications and provides a broad perspective of both areas. Proper materials and equipment for successful implementation into the curriculum must be chosen. A selected group of experiences has been designed to correlate specific information with creative experiences for students at the secondary level. 


\section{HISTORY OF LUSTERS}

Lusters and underglazes have been used by artisans for centuries to decorate and embellish the surfaces of clay wares. Even though these techniques are old, they are widely used by artists today to convey ideas, and are constantly being refined and redefined to fit changing styles in contemporary ceramics.

Sources seem to indicate that lusters were developed in

Persia. (Fig. 1) This technique was their greatest, single contribution to the field of art. ${ }^{I}$ The lusters appear to have first been used for decoration on glass between 700 and 800 A.D. ${ }^{2}$ The earliest known example of luster used on clay is a small bowl found at Fostat (Old Cairo). It is of Roman-Egyptian origin and dates to approximately the third century. Its alkaline copper blue glaze is flashed on the side with ruby red luster. Most likely, the flashing of luster was an accident. 3

The Persians dominated lusterware until the 13th century but continued production through the 16th century. They are responsible for the perfection and refinement of this highly controlled technique. ${ }^{4}$ The three major production centers were Rhages in North Persia, Sarra

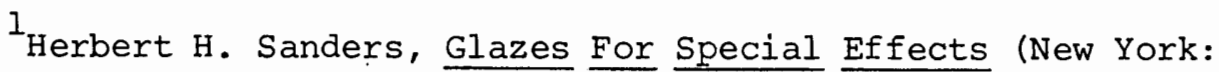
Watson-Guptill Publications, 1974), p. 92.

2 Thomas Shafer, Pottery Decoration (New York: Watson-Guptill Publications, 1976), p. 144.

${ }^{3}$ R. L. Hobson, A Guide to Islamic Pottery of the Near East (London: British Museum Publishers, 1932), p. 14 .

${ }^{4}$ Ibid., p. 14 
on the Tigris, and Rakka on the Euphrates in Syria. 5

The Persians' perfection of the luster technique may have been an effort to produce inexpensive substitutes for gold and silver wares. 6 Its popularity was also due to part to a directive by the Prophet Muhammed against the use of gold and silver vessels in an effort to help equalize the status of rich and poor. Seldom were lusters used as complete coatings on ceramic vessels.

Lusters were not produced for a while during the loth century. Historians are not sure of the exact reason, but have come up with three hypotheses:

1. It became too expensive to produce lusters.

2. Lusterware went out of style.

3. The technique may have become lost. 7

The Islamic potters created lusters of various shades and colors, including ruby reds, browns, greens, and yellows. 8 By the loth century they had refined and limited their palettes to tints and shades of yellows and browns because the more varied and brighter colors were extremely difficult to control during firing. ${ }^{9}$ These monochrome lusters were used to decorate wall tiles and dishes, including bowls, plates, and serving vessels. 10

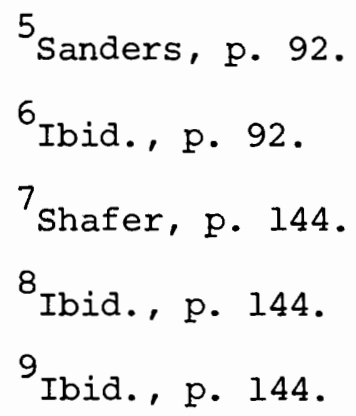


The Mongol invasion of Iran during the mid l3th century was a huge disaster with many important cities being destroyed, including Ray and Nishapurn, two large ceramic centers. Because of this, the luster technique spread to spain, most likely brought there by fleeing Iranian potters. The Hispanic Moresque wares of the 14 th and 15th centuries are considered by many to be the most magnificient achievement ever in the luster technique.

During the 13th century most lusterware in Spain was produced in Malaga and other Andalusian centers. ${ }^{11}$ By the end of the 14th century Valencia (reconquered by the Christians in 1238) had become the major lusterware center. Both Christian and Muslem craftsmen worked side by side in the potteries of Valencia which led to a beautiful blending of Gothic and Moorish styles. The lusterware produced in Manises, a suburb of Valencia, was the most desired pottery in Europe throughout all of the 15th century. 12

The Spaniards used light yellow to reddish gold lusters. ${ }^{13}$ In Spain, as well as in the mid-east, luster was most often applied over opaque white tin-lead glazes. Once in a while it was applied over a deep turquoise (alkaline) glaze which produced exceptionally beautiful results. 14

Sometime around the 1500 's, the use of lusters spread to Italy, 15

11

Shafer, pp. 144, 145.

12 Ibid. , pp. $144,145$.

13 Sanders, p. 95.

${ }^{14}$ Shafer, p. 146.

${ }^{15}$ Ibid. , p. 107. 
but the Spanish luster work always remained far superior to the work of the Italians. 16 Italian lusterware was highly valued by the aristocracy and was passed on through families for generations. 17 Lusters were probably used here as they were in Persia, to imitate gold vessels at a time when luxury was forbidden. 18

Deruta was the first center in Italy to use lusters. The ones used were generally pale yellow (made from silver) like earlier Hispano/Moresque ones. 19 Gubbio soon replaced Deruta as the primary lusterware center. Under the supervision of the master potter, Maestro Giorgio Andreoli, they produced the highly prized ruby red lusters, which were made from gold, as well as golden yellow and mother of pearl ones. 20 Majolica ware with and without highlights of luster was also produced here between 1520 and $1560 .^{21}$

A new development in glazing decoration was taking place in Italy at this time. Much of the decoration on the pottery was becoming more pictorial and narrative, with themes of biblical, mythological, and genre scenes. The themes were both original as well as derived from work of other artists. This new style was called "Istoriato". Often there was no regard at all for the shape or function of the pot

$$
\begin{aligned}
& { }^{16} \text { Shafer, p. } 119 . \\
& { }^{17} \text { Sanders, p. } 92 . \\
& 18 \text { George Savage, Pottery Through the Ages (London: Cassell }
\end{aligned}
$$
and Company Ltd., 1959), p. 88.

$$
\begin{aligned}
& 19 \text { Ibid., p. } 112 . \\
& 20 \text { Ibid., p. } 107 . \\
& 21_{\text {Conrad, p. } 95 .}
\end{aligned}
$$


when the design was applied. ${ }^{22}$ This style was something new in ceramic art, and since often the decorated surfaces were for display other than use, it was excused as an unsuccessful experiment. 23

The popularity of majolica with its bright shiny colors as well as the way it adapted itself to this new pictorial imagery gradually replaced lusterware in Italy. The fall of the city-state type of government also had a lot to do with luster's decline. Lusters were expensive to make and the fall of the government deprived the potters of their wealthy patrons, protectors, and benefactors.

There was also a decline in popularity of lusterware in spain at the same time which might have been attributed to the overthrow of the Moorish government. Following this overthrow there was religious opposition to all persons and material articles of Moorish influence and descent. At this time, all Moors were expelled from the country and anything related to them was destroyed or removed. The Eastern Mediterranean influence of both Chinese and Turkish ceramics was strong enough to replace almost all lusterware by the end of the 17 th century. 24

Following lusterware's decline in the Western Mediterranean area, there came a rise of a new luster process in Europe around the middle of the 18th century. ${ }^{25}$ This process consisted of firing liquid

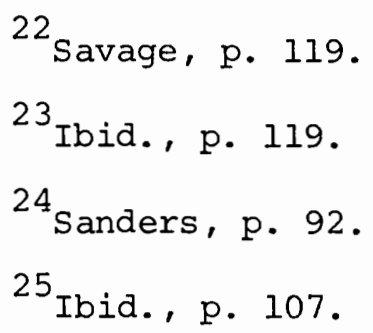


gold onto the surface of a fired glaze. This new gold process was first extensively used for decoration at Vincennes, France during the mid 18th century. (Fig. 2) This technique was used to highlight the finest works, with decorations derived from animals, vegetation, biblical scenes, and figures. Although there was a revival of interest in lusterware in Italy, Spain, England, and a small portion of Germany during the latter portion of the 18th and early part of the 19th centuries, the products were never comparable to the earlier Islamic and Spanish Iuster work. 26

The colors used by these later ceramic decorators were the same ones the Italians employed. They used gold which gave a pink to purple color, silver to obtain a yellow, platinum for silver color, and copper for red. 27

A large center in England at this time for luster production was Brislington, England. It was here that Bristol Delft was produced. Richard Frank, a potter at this pottery, is said to have produced the first English copper luster, around 1740.28

Wedgewood is believed to be the main discoverer of the methods of applying the lusters to English pottery and porcelain works, although there is also evidence that the first use of bronze luster should be credited to John Hancock from Etruria. 29

Although at first lusters were used to decorate only the highest

$$
\begin{aligned}
& 26 \text { Savage, p. } 160 . \\
& 27 \text { Ibid., p. } 114 . \\
& 28 \text { Conrad, p. } 95 . \\
& 29 \text { Savage, p. } 207 .
\end{aligned}
$$




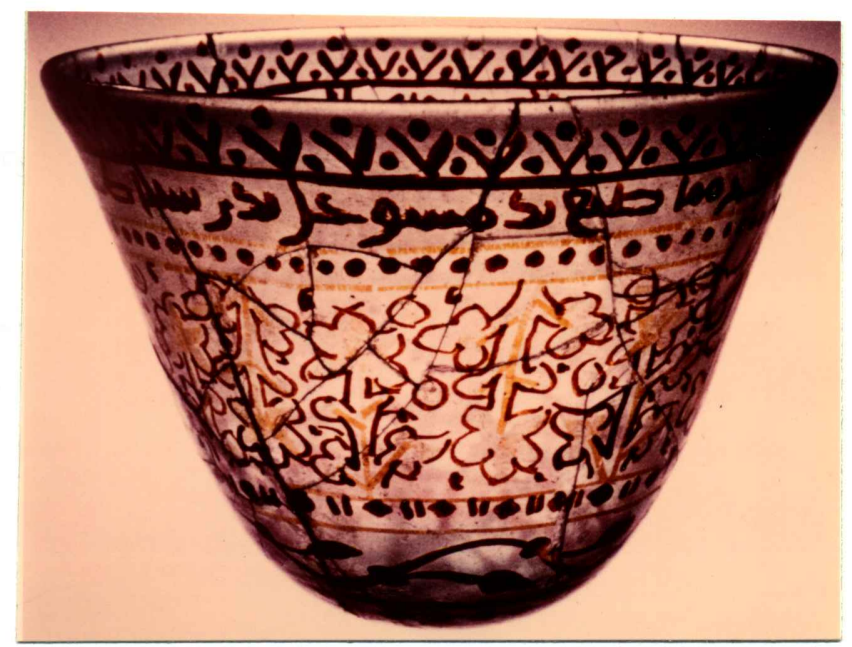

Figure 1. 8th century A.D. Islamic Luster Bowl. Corning Museum of Glass.

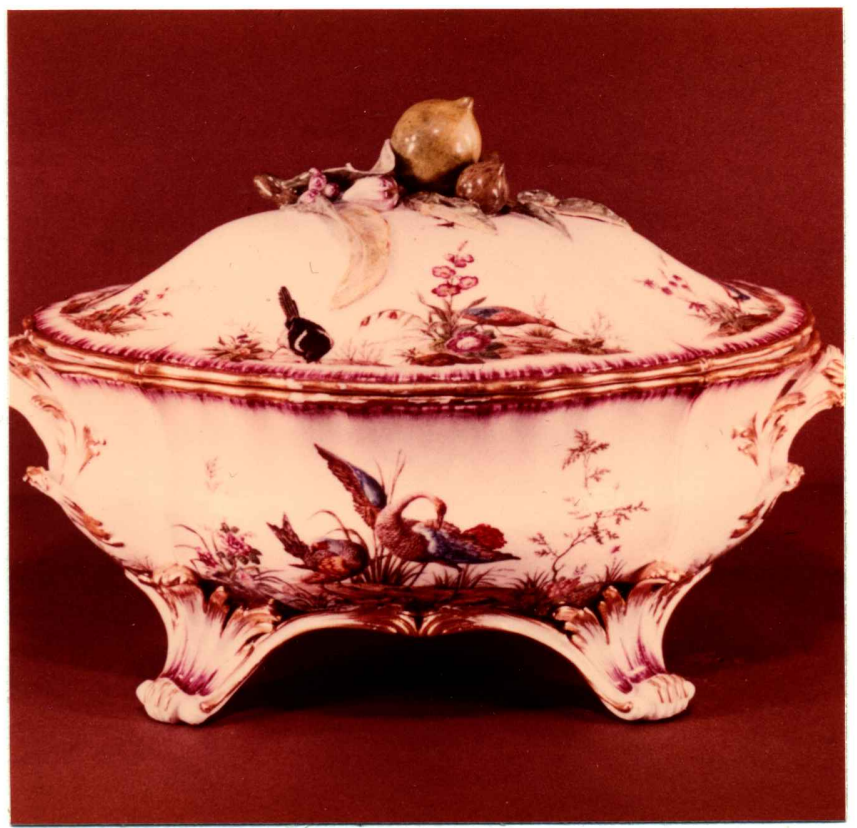

Figure 2. Vincennes Porcelain Tureen, 1752. The Cleveland Museum of Art. 
quality ware, after a while the inexpensive pottery was lustered as well. 30 As techniques improved it become increasingly difficult to tell silver-lustered ware apart from sterling silver pieces without actually touching the work. 31

At this time there were various methods of applying the lusters. The method of transfer printing in gold was invented by Peter Warburton early in the 19th century. It is similar to gold ceramic decals of today. There are very few examples of these, as they were only rarely used. 32 other methods used included covering the entire surface of a pot (known as "poor man's silver"), painting portions of the surface, or stenciling portions. 33

The copper lusters were the least valuable and so were made for the inexpensive ware. The use of lusters continued through all of the 19th century. Resist lusters were usually silver colored. Often, several different types of luster applications were used on a pot, although they were also used separately. More than one color luster could also be used on a pot. They were normally applied over light or white colored backgrounds on both pottery and porcelain.

The use of luster was extremely widespread. All of the factories in staffordshire used it, not only to embellish dishes and serving vessels, but also red earthenware sculptures. Lusters were

$$
\begin{aligned}
& 30 \text { Conrad, p. } 95 . \\
& 31_{\text {Ibid., p. } 95 .} \\
& 32 \text { Savage, p. } 30 . \\
& 33 \text { Ibid., p. } 207 .
\end{aligned}
$$


also produced in factories in Bristol, Sunderland, Newcastle, Swansea, Liverpool, and a number of smaller towns. 34

As time advanced, lusters also moved on, but their value

became lower. Whereas they once were used on items of value they were later picked up by industry to decorate (and overdecorate) quickly and cheaply in addition to poorly imitating more expensive and beautiful work. Lusters were used for a long time to simulate metal until a cheap method of electroplating metals to ceramics was found. 35 As well as this often tasteless lusterwork, artisans of the 20 th century also started using lusters to embellish the surfaces of their clay works with more aesthetic concern. In the early 1950's Picasso started using lusters to heighten the effects of some of his works. 36

Clay, once traditionally used to make pots or figurative sculptures was now being used to make anything an artist desired. The clay was pushed and pulled and often the surfaces were embellished with lusters and brightly colored glazes. 37

People were starting to look for unique objects to purchase by the 1950's. Artisans started becoming more creative to keep up with the demand. More and more craftsmen were turning to colleges and universities, where crafts were beginning to be taught in art departments,

${ }^{34}$ Savage, pp. 207, 208.

${ }^{35}$ Conrad, p. 95.

${ }^{36}$ Emmanuel Cooper and Eileen Lewenstein (ed.), New Ceramics

(New York: Van Nostrand Reinhold Company, 1974), p. 18.

37 Ibia., p. 19 
for their training. 38

Fredmeyer writes, "Although design once meant applied decoration, it is now known as 'creativity', the soul of the piece." 39 Rose Slivka writes in "The Persistent Object", "He (the craftsman) is trying to create not necessarily new objects, but new attitudes towards objects, to reinvest the object with its original intrinsic reality, value, and power. Crafts, which functioned in the communal or regional culture of an agrarian (agricultural) society do not have the same meaning in the internationalized centure of an industrialized society." 40 Before, a craftsman often knew who his buyer was and why the object was being requested, but now, although some still make to order, many in this mechanized society have no idea who the buyer will be or what use his product will be called upon to serve. So, often a potter will produce work highly related to himself and hope that a consumer will want the particular item. 41

It wasn't more than 100 to 150 years ago that the development of crafts was supported by dukes and kings who ruled independent localities. The crafts of their areas were used in competitive displays of their power and wealth. 42

${ }^{38}$ Lee Nordness, Objects: USA (New York: The Viking Press, 1970), pp. 11, 12 .

39 Ibid. , p. 19.

40 Rose Slivka (ed.), The Crafts of the Modern World (New York: Bramhall House, 1968), p. 13 .

41

Ibid. , p. 13.

42 Ibid., p. 16. 
Now, much art work can be bought by more average, middle class citizens today than ever before. The population now also has many opportunities to view great work via galleries, shows, and museums. Art is now being brought to the public instead of being reserved for the elite.

Crafts, throughout history, have produced useful items which, as the years pass, are later considered fine art. Time seems to have a way of lessening the functional significance of objects. ${ }^{43}$ Potters since the fifties, like Picasso, have begun to reflect more and more of themselves, their environments, feelings, and thoughts into their work. ${ }^{44}$ old techniques were revived and modified and new methods were invented. There was interest in brush decoration. With it, the freshness of a sketch could be brought to the surfaces. Many potters agree that the Abstract Expressionism of Pollock, DeKooning, and Kline finally freed potters from tradition, conventionalism, and the limitations of the materials themselves. 45

Alan Caiger-Smith, an English potter, is quoted as saying, "A problem for a potter is how to justify a lifetime of making ceramics in a changing Britian which does not need them as vessels and which should not be offered them as trifles." 46

He feels that lusters are an appropriate decorative media

43 ${ }^{4}$ Slivka, p. 20.

${ }^{44}$ Paul S. Donhauser, History of American Ceramics: The Studio Potter (Dubuque: Kendall Hunt Publishing Company, 1978), p. 135 . ${ }^{45}$ Ibid. , pp. 139, 146, 147. ${ }^{46}$ Cooper and Lewenstein, p. 30 . 
because although they have a traditional background they can still be used to give new joy and exhilaration to modern ceramic works. ${ }^{47}$ Because of the increased mass production of pottery it seems natural that by the sixties ceramic artists and potters were becoming more and more concerned with embellishing the surfaces of their works and turning them more into art objects than functional wares. Many potters were finding that they considered the decorated surface the main indicator of beauty, not the utilitarian purpose of a pot. ${ }^{48}$

Many potters are now using lusters, including william Crevitz, Rudy Autio, ${ }^{49}$ Mutsuo Yanagihara, ${ }^{50}$ and Erik Gronborg. (Fig. 3) These potters use lusters primarily for highlights and embellishments. Yanagihara does patterned geometric works ${ }^{51}$; Gronborg does hand-built pieces embellished with sculpture, imprints, photo-silkscreen, and luster; Autio uses lusters and engobes to embellish both large rather rough slab pieces as well as more refined forms; and Crevitz creates wheel thrown ware with luster decorations on top of stoneware glazes. 52 The more well known and famous modern ceramic artists currently using lusters are Robert Sperry, Howard Kottler, Fred Bauer, and Patti Warashina. Their works have directed the course of ceramics from the

${ }^{47}$ Cooper and Lewenstein, p. 29. ${ }^{48}$ Slivka, p. 223.

${ }^{49}$ LaMar Harrington, Ceramics in the Pacific Northwest (Seattle: University of Washington Press, 1979), p. 41 .

${ }^{50}$ Cooper and Lewenstein, p. 181.

${ }^{51}$ Ibid., p. 181.

52 Ibid., p. 181. 
sixties on.

Howard Kottler has worked at the University of Washington since 1965. His aim is to produce objects for people who don't need anything. This, he calls "palace art". He wants his work to be expressive of his personality, rather than being functional ware. His work intensified the transistion from functional to nonfunctional work, especially in the Northwest. 53

Robert Sperry, also of the University of Washington, always pays particular attention to the pot. He doesn't want it to lose its importance. The works he lusters vary from extremely traditional pot forms with patterned lusters to sculptures with luster embellishments. His works are currently centering on more traditional forms, moving away from large abstract sculptures. In justifying his more traditional work, Sperry argues that sculptures can be made with success in many materials to form the same shape, but only clay and a potters wheel can make pottery. 54

Most intensely committed are Fred Bauer and Patti Warashina. Both work in the area of innovative sculptural objects. Their work has been influenced greatly by surrealism, especially Arshile Gorky and Joan Miro. Their works show much "free association", where an image of a common thing is developed into a major fantasy. With titles such as "Admiral Bird as a Ball and Socket Joint Pondering a Square Ice Whole" (Bauer) (Fig. 4) and "Car Kiln" (Warashina) (Fig. 5) they seem to stretch "free association" as far as it will go. They

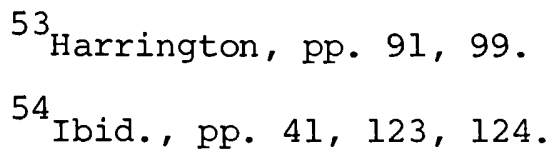




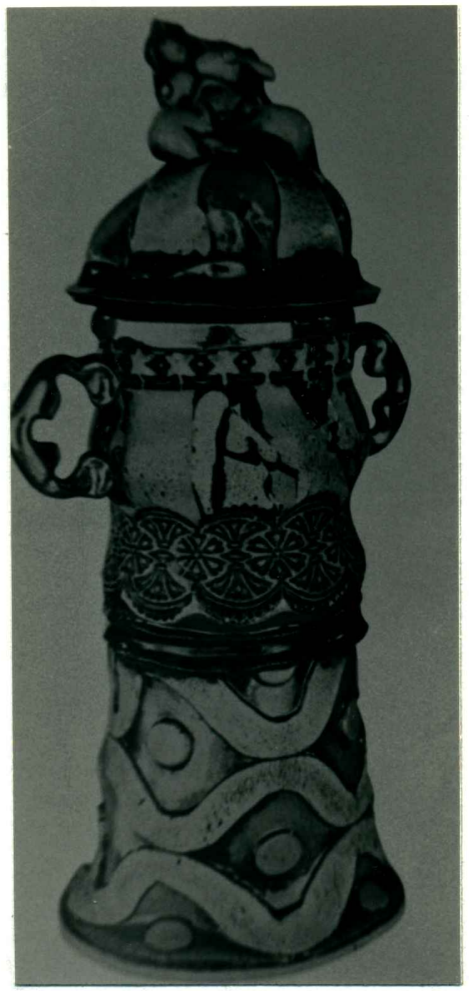

Figure 3. "Container With Lid", 1974. Erik Gronborg. The Oakland Museum.

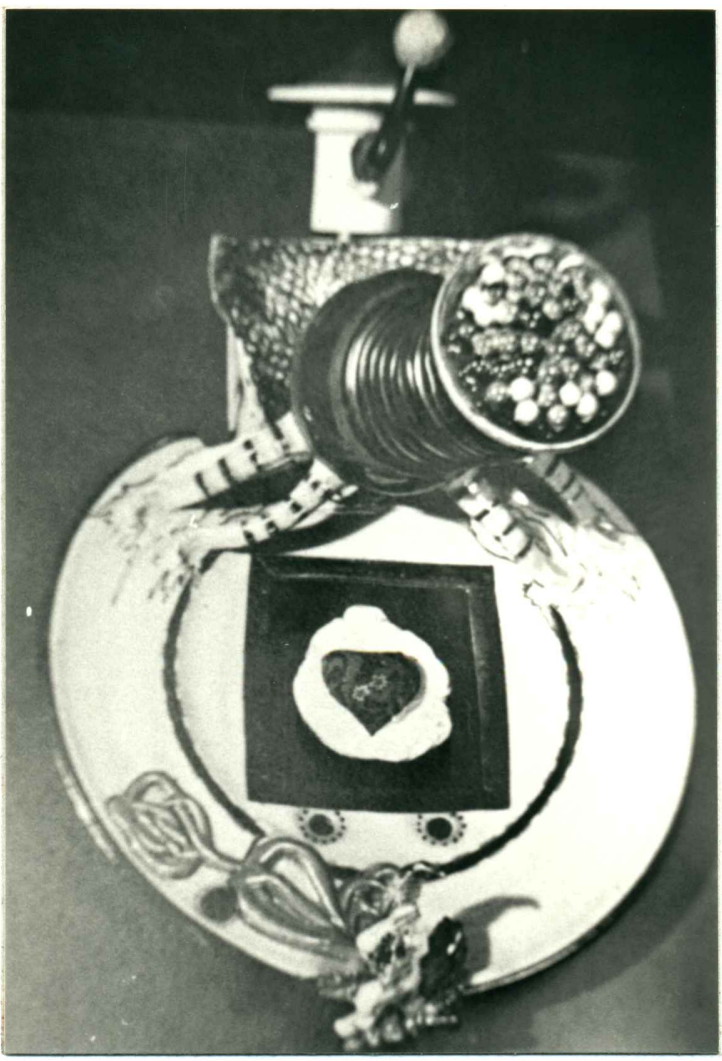

Figure 4. "Admiral Bird as a Ball and Socket Joint Pondering a Square Ice Whole", 1969. Fred Bauer. Collection of Robert L. Pfannebecker, Lancaster, Pa.

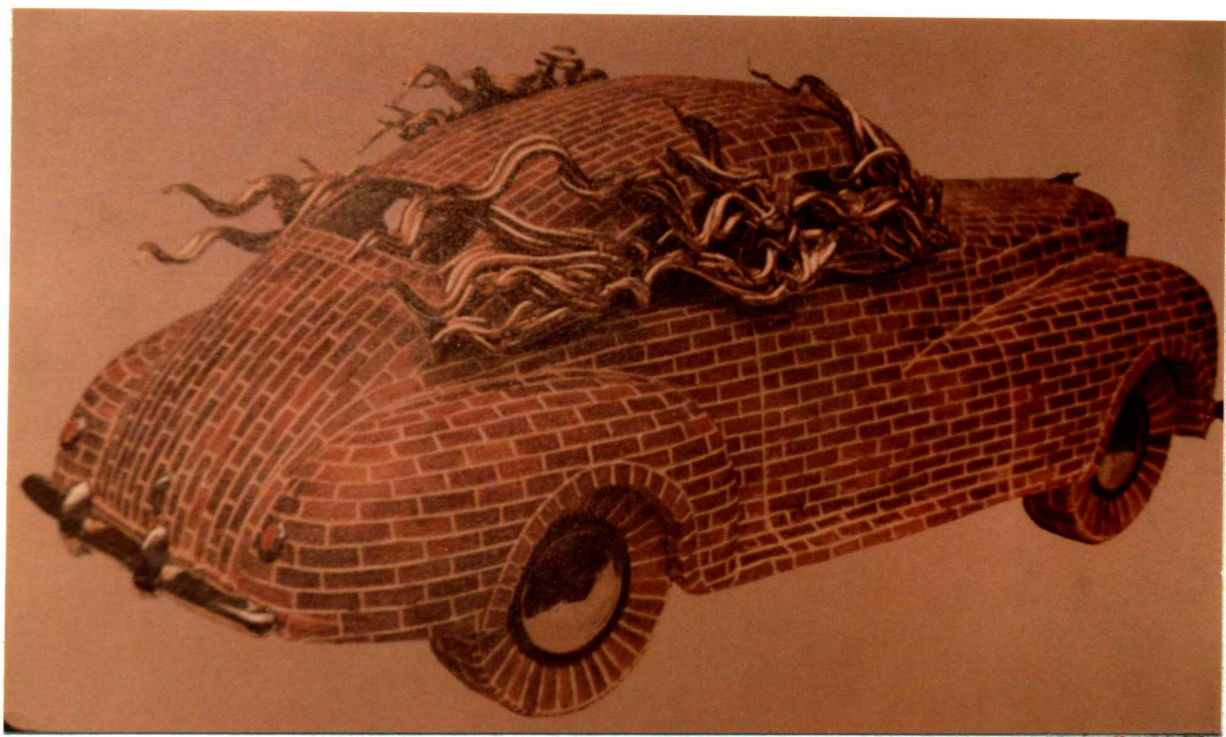

Figure 5. "Car Kiln", 1972. Patti Warashina. Collection of Robert L. Pfannebecker, Lancaster, Pa. 
both enclose little cosmic worlds and narrations in much of their work. While Bauer tends to make each work separate and distinct, Warashina builds each work upon the other in series, the next one starting where the other left off. 55

\section{VARIOUS LUSTER TECHNIQUES}

\section{All lusters deposit a thin metallic film on top of the glazed} surface. Lusters, throughout history have been refined to suit the needs of ceramic artists by making them easier to apply and fire, as well as making the finished results much more consistent and reliable. To be more fully appreciative of modern-day lusters it is important to be aware of other older luster methods.

The earliest lusters that the Persians, Spaniards, and Italians used are known as "smoked Arabian lusters". These lusters were applied to glazed pottery in the form of pastes or paints. ${ }^{56}$ They were made of pure metallic salts or carbonates. These salts could be used plain or mixed with other carrier materials, such as ochre clays combined with small amounts of gum or starch to make them easier to apply and to aid in their adherence to the pot before firing. Three parts ochre to one part metallic salt or carbonate, by weight, has been found to be suitable. The ochre, color, and gum or starch mixture was ground to a smooth brushing consistency before it was applied.

Traditionally, the salts used were copper sulfate, silver nitrate, gold chloride, bismuth subnitrate, copper carbonate, stannous

${ }^{55}$ Harrington, pp. $71,123$.

${ }^{56}$ Shafer, p. 147 . 
oxide, silver carbonate, and mercury sulfide. Copper produces reds, salmons, and golds; silver produces yellows and ivorys; gold produces reddish purples; and bismuth produces a mother of pearl type iridescence. 57 Sample smoked arabian luster formulas will be found in the appendix. The glaze over which these lusters are applied should have a maturing temperature which is higher than the luster. White or light colored glazes show off the lusters the best. Lead based glazes which also contain tin produce the best surfaces. 58 But, one must be careful, because if too much lead is present, the luster may darken or gray a little. Experimenting with different glazes is recommended. The luster will only be as shiny as the glaze over which it is applied. 59

Arabian lusters are fired to around $1220^{\circ} \mathrm{F}$ (dull red heat). The temperature should be hot enough to assure that the glaze becomes tacky so the luster can attach itself firmly. Once temperature is reached the burners should be turned down but a reduction atmosphere should be maintained until $1000^{\circ} \mathrm{F}$. The kiln is then shut off and allowed to cool at its own rate, still maintaining a reduction atmosphere. When the ware is cool, the pigment will be black. Washing the blackened area with a mild abrasive and then lightly burnishing it will leave only the metal deposit. 60

${ }^{57}$ Daniel Rhodes, Clay and Glazes for the Potter (Philadelphia: Chilton Book Company, 1957), pp. $\frac{183,284 .}{283}$

58 Conrad, p. 97.

${ }^{59}$ Rhodes, p. 284.

60 Ibid., pp. 118, 119. 
This type of luster may also be fired in an oxidation kiln by firing to the required temperature, shutting the kiln off, and letting it cool down $200^{\circ}$. When the $\mathrm{kiln}$ is ready, remove the object one wishes to luster fire and place it in a metal container which has been filled with shredded carbonaceous matter (dry leaves, sawdust, or shredded newspaper) and close the lid tightly. Remove the piece when the temperature in the container reaches $500^{\circ} \mathrm{F}$. Polish as for reduced luster. This method is an extremely close relative of raku firing. ${ }^{61}$ Flash lustering is another luster method. It was a method which was seldom used. Flash lustering produces an overall luster effect. It is an older technique which was revived as new in 1911 by Louis Franchet. 62

This method calls for the addition of the metallic salts or carbonates directly to the base glaze. The glaze is fired to its maturation temperature and is then reduced during the cooling cycle between an hour and an hour and a half. The reduction should be started at around $900^{\circ} \mathrm{F}$, it should be heavy for the first half hour and of medium strength until the kiln darkens. This technique can be used as a majolica-like technique in sections on top of the glazed pot. This will give the added on portion of the glaze a raised surface. This technique has an advantage in that it only requires one firing, but the results are extremely erratic and inconsistent, making it undesirable to use. 63 sample formulas will be found in the appendix.
${ }^{61}$ Conrad, p. 106.
62 Sanders, pp. 104, 105.
${ }^{63}$ Ibid., pp. 107, 108, 109. 
Fuming is another seldom-used method of lustering. It does not produce powerfully colored results. Instead, it gives an iridescent mother of pearl coating to the entire piece. Sometimes the coating is extremely evident but sometimes there is barely a hint of it. Fuming is usually done with stannous (tin) chloride, but can also be done with strontium nitrate and barium chloride mixed in with it in amounts up to $20 \%$. These salts form red and blue coloration. Other less effective salts may also be used alone or in combination with each other, including: chrome nitrate, barium nitrate, sodium nitrate, zinc nitrate, bismuth subnitrate, silver nitrate, copper sulfide, and iron chloride.

Most glazes, including lead-based ones, can be successfully fumed. The ware is fired to temperature in either an oxidation or reduction atmosphere. When the kiln has cooled at its own rate to $1400^{\circ} \mathrm{F}$ all openings are closed until the temperature is a uniform $1300^{\circ} \mathrm{F}$. At this temperature the objects are just barely visible. When the kiln reaches $1300^{\circ} \mathrm{F}$ pilot lights, burners, or blowers (if there are any) are turned on low to help spread the fumes. At this time the volatile salt being used is deposited, via a long spoon, into the kiln, through a porthole, firebox, peekhole, or stack. Heating the spoon to red hot before filling will insure better results. Several small spoonfuls of material are better than one large one. Approximately 50 grams of tin chloride will fume a kiln of ten cubic feet.

The material, upon introduction into the kiln will burst into 
flames that the blowers will spread around. If there are no blowers the material must be moved about in the kiln to several different locations. The kiln must be sealed tightly to prevent fumes from escaping. Draw rings should be removed to determine if more fuming is necessary.

If the temperature in the kiln is too high or the volatile material falls directly on a pot, a white or gray scumming may appear. 64 There are several other specialized methods of fuming pottery. One is known as pan fuming. In this method an individual piece may be fumed by heating the volatile material in a pan over a hot plate. When the kiln has cooled to dull red, the piece to be fumed is removed with tongs, rotated over the fuming chemicals several times, and returned to the kiln to cool at the kiln's rate. The temperature of the removed piece is above the quartz inversion temperature, so there isn't likely to be much breakage. 65

The other specialized fuming technique involves fuming salt glazed ware. When the kiln has cooled to dull red heat, the fuming salts are introduced into the kiln in heated long handled spoons, using the same method as for regular fuming. Because of the high soda content in the salt glaze they take color well and become highly iridescent. 66

Because metal fumes are toxic to the eyes and lungs, it is a good idea when fuming to wear a gas mask, unless the kiln has a hood.

${ }^{64}$ Conrad, pp. 104, 105.

${ }^{65}$ Ibid., p. 105

${ }^{66}$ Rhodes, p. 285. 
The metal compounds also can cause a skin rash, so the salts should not be touched. 67

Although traditionally lusters have been fired in reduction atmospheres the newer manufactured lusters are made to be fired in oxidation atmospheres. Although some lack the depth of the older, reduced types, the ease in application and firing as well as the consistency of the results make them extremely desirable. 68

This type of luster is called a resinate luster. Commercial lusters contain a resin which acts as its own reducing agent. This is the type of luster which was used until a cheap method of electroplating was found. It is now mainly used for small areas of decoration and embellishment on pottery by contemporary ceramic artists. 69 Students will use this type of luster in testing this thesis.

These lusters are made by combining metallic salts, chlorides, or nitrates with a resin (usually sodium resinete) and some type of oil (usually oil of lavendar). This solution is mixed thoroughly, then allowed to rest for a day. It is then filtered and again allowed to rest for five to ten days. After this, it is ready to apply to glaze fired pottery either by painting or spraying. 70

Although it is possible to make one's own lusters (see appendix for formulas) it is easier and the results more consistent if one uses commercially prepared ones. If a commercial luster thickens it

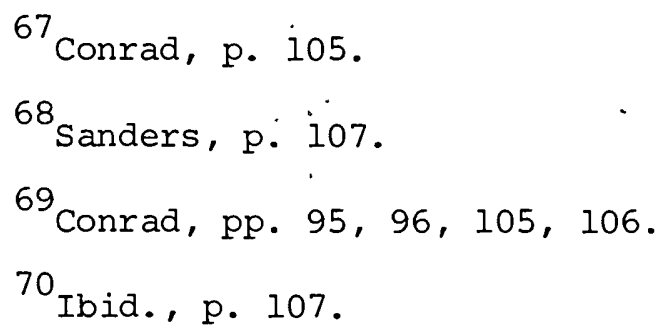


may be thinned for continued use by adding a little luster essence.

For applying lusters the fired ware must be scrupulously clean, (dust, lint, and fingerprint free) dry, and at room temperature. Guidelines for luster placement may be applied either with a felt tip pen, graphite paper, or with draftman's tape that has been firmly sealed down. The tape is especially useful in the application of stripes and checks. The studio in which lustering will be done should be clean, dustfree, and as clear of humidity as possible. ${ }^{71}$

It is best to start out with an easy to apply and inexpensive luster, such as mother of pearl. Later, when one gains more skill, more expensive and harder to apply lusters can be used both singularly or in combination with each other, such as mother of pearl over platinum. $^{72}$

It is important to remember the lusters will reflect what is underneath them. They will only be as shiny as the glaze upon which they are applied.

The lusters will appear brownish when applied, but will obtain their proper colors after firing. Each coat of luster must be fired separately. There are no shortcuts that can be taken, if one wishes to achieve good results.

The lusters may be applied with camel hair brushes, quills and reeds, steel pens, airbrushes, or luster pens. ${ }^{73}$ The students will use

\section{${ }^{71} \mathrm{Nils}$ Cederborg, The Art of Lustre Painting (Colombus: Nils} Cederborg Associates, no date), pp. 2,10 .

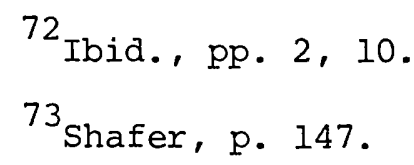


camel hair brushes and luster pens for all work done for the testing of this thesis. The lusters need to be applied in a thin, even film. If the coating is too thin, the lusters will be dull, not shiny, and if the coating is too thick the lusters will blister and flake off. 74 If using a luster pen, use it like a felt tip pen to write or draw on the surface of the pot. These pens are exceptionally good for small designs and writing. When using a brush there are more steps. When dipping the brush, do not dip so deeply that luster gets under the metal ferrule. Luster caught under the ferrule will be almost impossible to remove completely and can then contaminate other lusters if the same brush is used. 75

For banding, the pot must first be centered on a banding wheel. It is best to always start painting below the rim and work upwards, then back down again. When the brush runs dry, re-dip, and again start below where you left off, work up to overlap, then work down again. This process will prevent a large buildup of luster at the beginnings and endings of the brush work.

Luster work should be done quickly, because lusters dry rapidly. If it isn't, the luster will pool in rings that look quite unattractive when fired. For small areas and designs which a brush width will cover or almost cover, speed is, again, of essence. With this type of design, as well, one must still be careful to assure there is as even a coat of luster as possible, not a big buildup of luster along the edges.

$$
\begin{aligned}
& { }^{74} \text { Shafer, p. } 147 . \\
& { }^{75} \text { Cederborg, p. } 3 .
\end{aligned}
$$


Five to ten minutes should be sufficient time to allow the lusters to dry. They should not be touched to test. At this time any striping tape may be removed. If any smudges or luster out of place are present they may now be removed by dipping the corner of a folded crisp sheet of paper into turpentine and carefully removing the mistake with the paper's edge. Do not try to touch up minor mistakes or unevenness on the decoration itself. This will do more harm than good. These types of minor imperfections usually correct themselves during firing. Be careful about the amount of turpentine used. Too much can creep into the decoration and cause a fuzzy edge, or worse yet, if dropped directly onto the decoration will cause a mottled effect. It is important to clean the edges more than once. Often there is a residue which is not visible, but which will still fire on. If the mistake is extremely large or unfixable it is best to wash the surface off completely with turpentine and then to start lustering all over. 76

Once mistakes, if any, have been cleaned up, the completed piece should be moved to a warm, dust-free place until it is fired. Dust will cause specks when the luster is fired. 77

When stacking the ware in the kiln, there should be plenty of room between the pieces as well as between the pieces and the shelves above them. This open stacking will provide the needed ventilation. The ware should be fired only with other luster pieces, not with overglazes or decals. Ventilate the kiln well by removing

${ }^{76}$ Cederborg, pp. 2, 3 . 77 Ibid., p. 5. 
the plugs and leaving the lid ajar. The fumes are extremely strong, and if they can't escape they cover the ware with a dull film which is very difficult to remove without scratching the lusters.

Either gas or electric kilns may be used, as long as the atmosphere remains in oxidation. The lusters are fired to cone 018 $\left(1323^{\circ} \mathrm{F}\right)$. As the temperature in the kiln rises, the pots will turn black. This is a result of the reducing agent within the luster burning. After a while this black will disappear. At this point the kiln may be closed and firing finished. The kiln should be shut off immediately when temperature is reached to avoid overfiring the lusters. $^{78}$ A sample firing schedule for an electric kiln is as follows:

\begin{tabular}{lll} 
Kiln Setting & Lid Position & Time \\
\cline { 2 - 3 } Low & Open & 1 hour \\
Medium & Open & $1 \frac{1}{2}$ hours \\
High & Open & 1 hour \\
High & Shut & until completion
\end{tabular}

When the ware is removed from the kiln, a thin film of metal will have been deposited wherever the luster was used. If desired, the luster may be buffed with a soft cloth to bring out a bit more sheen, although this is usually not necessary. If, upon removal, one finds areas of luster which should have been removed before firing, it is possible to remove them with ordinary liquid rust remover, being careful not to get any remover on the rest of the design. 79

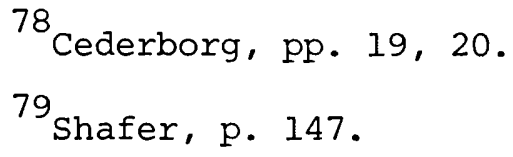


"As with many other traditional techniques, luster still has a potential not yet fully exploited in contemporary work." 80

\section{HISTORY OF UNDERGLAZES}

Since engobes are forms of underglazes, they will be discussed, although the students will not explore their uses.

As well as being the first people to use and perfect the luster technique, the Persians were also the first to use underglazes. They used cobalt blue, which was only later adopted by the Chinese during the Yuan Dynasty (1279 to 1368 A.D.). 81

Painting with colored engobes is one of the oldest forms of pottery decoration. It was most likely one of man's first conscious acts of coloring clay vessels. It is extremely widespread. Pots have been found that are six to seven thousand years old that have colored engobe decorations. Engobes, now usually used in combination with glazes, were used alone at first. Only later did they come to be used in conjunction with glazes.

By the 5th millenium B.C. there was sophisticated pottery decorated with engobes being made in Persia, Mesoptamia, and Egypt. These pots usually had an all-over decoration in red applied over a white or cream engobe ground, although there were exceptions. ${ }^{82}$ (Fig. 6)

Engobes appeared in the Minoan culture between 2000 and 1400 B.C. In the Minoan culture, decoration centered mainly on sealife and design

$$
\begin{aligned}
& 80 \text { Rhodes, p. } 285 . \\
& { }^{81} \text { Savage, p. } 26 . \\
& 82 \text { Shafer, p. } 86 .
\end{aligned}
$$


forms. The Minoans were a vigorous and dynamic people whose lust for Iife showed in their ceramic work. They had a wonderful sensitivity for the relation between form and decoration. 83 "Their curvilinear and spiral designs were very bold and self-assertive, yet perfectly enveloping and enhancing the full, round forms." 84

The Greeks also produced beautifully ornate pottery with a limited palette of natural engobes. Their decorations revolved around figures, animals, and people and were mostly connected with religion. 85 (Fig. 7)

Both the Greeks and Romans used a technique called terra sigillata, which involved burnishing the surface of the red, brown, or black engobes until a rich patina was obtained before firing. This patina remained even after the work was fired. It is a technique quite similar to one used by American Indians of the Southwest, Mexicans, and South and Central Americans. 86

In addition to terra sigillata, the Romans also used trailing, a technique which forms a raised design or picture. This technique has been used consistently throughout the history of underglaze decoration. 87

By the time the Chinese adopted underglazing during the Yuan

${ }^{83}$ Savage, pp. $45,46$.

${ }^{84}$ Ibid. , pp. $45,46$.

${ }^{85}$ Ibid. , p. 52 .

${ }^{86}$ David Hamilton, Manual of Pottery and Ceramics (Toronto: Thames and Hudson Ltd., 1974), p. 112 .

87 Ibid., p. 108. 


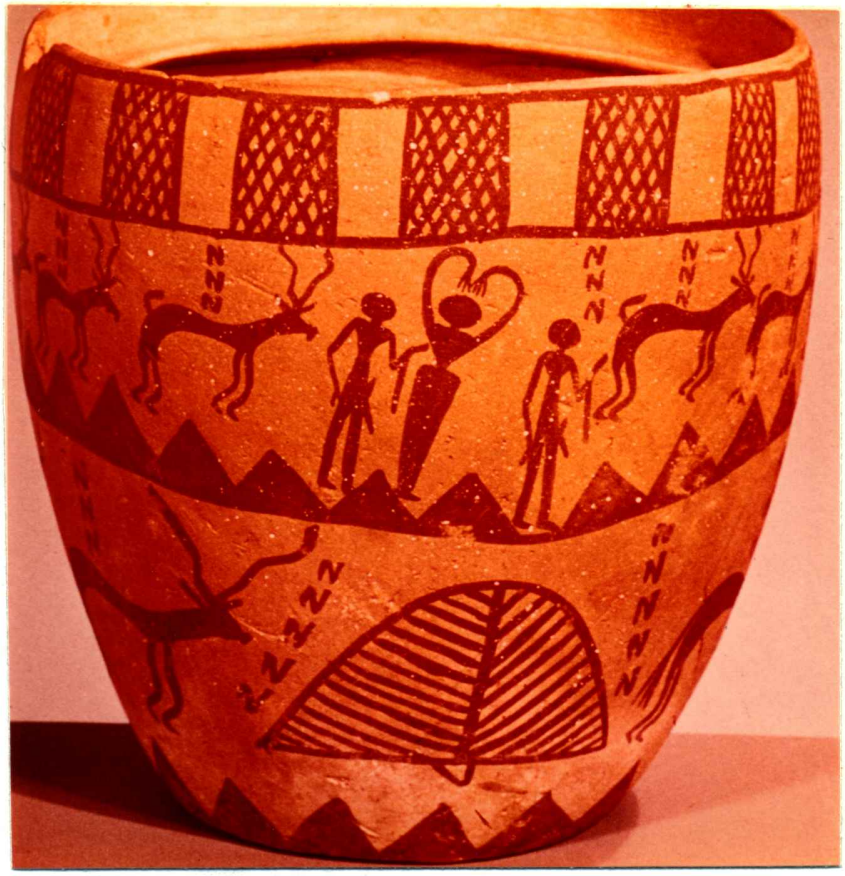

Figure 6. Egyptian Pre Dynastic Vase. The Metropolitan Museum of Art.

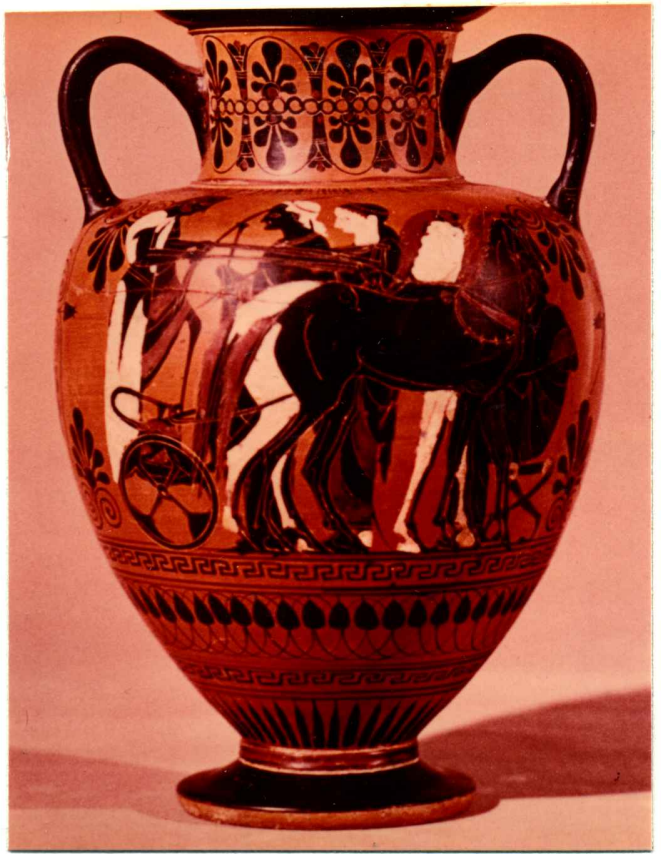

Figure 7. Greek Amphora, 520 B.C. The Dayton Art Institute. 
Dynasty, the white engobes were beginning to be colored with metallic oxides. Although the Chinese did use different colors of engobes including greens and browns, they are most well known for their use of cobalt blues. (Fig. 8)

Their underglaze paintings were done under a transparent or semi-transparent glaze, usually on porcelain. Their blue and white porcelains of the Ming Dynasty (1368 to 1643 A.D.) were famous for their gorgeous blue and white decoration. The Chinese derived their decorations from nature, both animal and vegetation. Their patterns were noted for being exceptionally crisp and detailed. They were usually outlined in dark blue and had the insides filled in with different, lighter shades of blue.

The Chinese work inspired, both for ideas as well as direct imitations, many other cultures, including Japan, the Mid-East, Europe, and Korea. 88

The Koreans used a technique called mishima on porcelain. In this technique impressions were made into the clay, filled with colored engobes, then smoothed over. The French picked this technique up, modifying it a little by making their impressions with stamps, during the 1500 's. 89

Turkish Iznik ware from the late 16th to early 17 th century was probably the most sumptuous of all early underglaze work. It consisted of beautifully flowing, stylized floral designs done on

$$
\begin{aligned}
& { }^{88} \text { Shafer, p. } 92 . \\
& { }^{89} \text { Savage, p. } 141 .
\end{aligned}
$$


a white engobe background in black, blues, greens, and iron red. 90

From the latter part of the 17th century on, trailing came

back into use. Potters of Staffordshire, England are the most well known for it. They used a white ground trailed with a reddish brown. 91 The most well known of the staffordshire potters were Thomas and Ralph Toft. Decoration on their work was primarily of a biblical nature. 92

At about the same time, the Dutch were beginning to make Delft tiles. These tiles were usually produced in varying shades of blue. Variations of these tiles are still being produced today. 93

In about 1830 Josiah Wedgewood's factory was producing light blue and white Wedgewood relief sculptures, pots, and vases. These Wedgewood works use much blue underglaze with even an occasional touch of gilding. 94

In 1856, Thomas Whieldon, a former partner of Wedgewood's, started producing his own type of engobe work called "agate ware". This ware was made by painting a pot with engobes and dropping additional colored engobes made from either manganese, copper, cobalt, ochre, or antimony, onto the wet surface. While the engobes were still wet the surface was combed, thus producing a marbeled surface. The

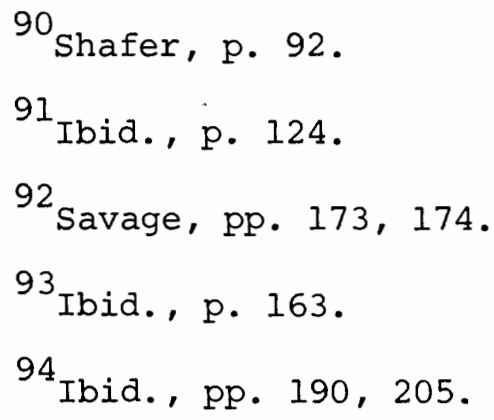


final piece was covered with a transparent glaze. 95 This was a new and fresh approach to underglaze decorating, which had been used before as an exacting way to depict and commemorate.

As well as his agate ware, Whieldon also did a lot of relief work on pottery. His sculptural forms were usually useful and quite humorous. 96

In addition to being used in Europe at this time, decoration with engobes was also being used in the United States. American Indians in the Southwest were using natural engobes (reds, browns, black, and white) to paint geometric designs of religious and mythological origin onto their pottery. Usually, most of the pot would be covered with decoration. Similar decorations are still being employed today. 97

In 1871 a French ceramist, Ernest Chaplet, invented the barbotine technique of underglaze painting, which is the immediate forerunner of "modern" underglaze painting and would have a great effect on "Art Pottery". The underglazes for this method were made from finely ground colored clays which were then painted on an unfired dry pot, covered with a clear glossy glaze, and fired. 98

The Haviland-Auteuil factory started using this technique soon after its invention. Its sudden popularity was due primarily

95 Ibid. , pp. 185, 186.

96 Ibid., pp. 186, 187.

97 Shafer, p. 86 .

${ }^{98}$ Kirsten Hoving Keen, American Art Pottery 1875-1930 (Wilmington: Delaware Art Museum, 1978), p. 5 . 
to two reasons. Its slightly raised surface was similar to the surface of oil paintings and a ceramic decorator could justify their work because it was similar to "finer" art. Also, it was a two dimensional approach to decorating the surfaces of three dimensional forms with designs which had once only been appropriate for use on paintings and drawings.

Between 1875 and 1930 a type of pottery known as American Art Pottery was being produced in the United States. It was a specialized type of pottery, produced primarily for its aesthetic value, although it did have a recognizable utilitarian form. This form was often ignored because of the beautiful decoration, however. There was great variety in styles and influences, including Oriental and French Art Noveau, as well as original ideas from the individual potters. 99 Mary Louise McLaughlin, a china painter, who worked in Cincinnati, Ohio during the late 1870's started using underglazes in combination with slips, instead of china paints, after the Philadelphia Centennial Exhibition in 1876 where the barbotine technique had been present.

In April of 1879 fifteen women organized a pottery club and elected McLaughlin their president. Their meetings were held in industrial studios, first in the Coultry Pottery, later in the Dallas Pottery.

Although the men still threw the pots (until the 20th century), the women were no longer painting china blanks for a hobby. They ${ }^{99}$ Ibid., p. 7. 
were moving towards a professional approach to pottery decoration and manufacture. The decoration they used was based upon floral motifs, but the designs stayed functional and compatible with the forms. 100

As well as the Cincinnati Pottery Club, another pottery was formed, called the Rookwood Pottery, founded by Maria Longworth and George Ward Nichols. Both the Cincinnati Pottery Club and the Rookwood Pottery were noted for their experimentation with underglaze and exotic shapes which flowed over the entire surface of the ware. The Rookwood Pottery further developed the design motifs by including human, animal, and vegetation shapes in their repertoire. 101 (Fig. 9)

The fluid qualities of the underglaze helped contribute to the flowing and rhythmical qualities the designs took on. The designs and decoration were no longer limited only to bands and geometric shapes. 102 In 1880, McLaughlin filed suit against the TJ Wheatly pottery, who claimed to have invented the barbotine method, calling it instead, the "Limoges method". They had asked for a patent on it, but McLaughlin won her suit, thus preventing them from obtaining the patent. 103

Because this new underglaze technique was a more painterly type of decoration, it started to make an obvious division of the labor forces in pottery, separating the decorators (usually female) from the potters and mold makers who were usually male. The decorators worked hard to keep themselves one notch above the potters, who only

$$
\begin{aligned}
& 100 \text { Ibid., pp. } 8,9 . \\
& 101 \text { Ibid. , p. } 9 . \\
& 102 \text { Ibid., p. } 9 . \\
& 103 \text { Ibid. , p. } 9 .
\end{aligned}
$$




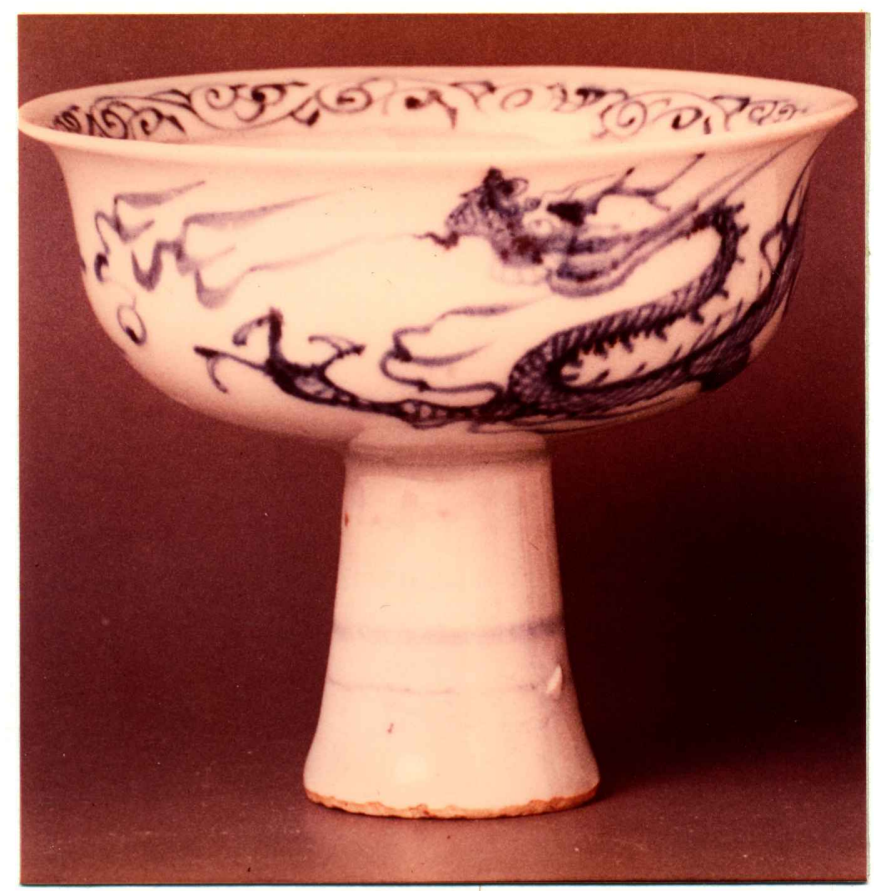

Figure 8. Yuan Dynasty Porcelain Stem-Cup. M. H. de Young Memorial Museum.

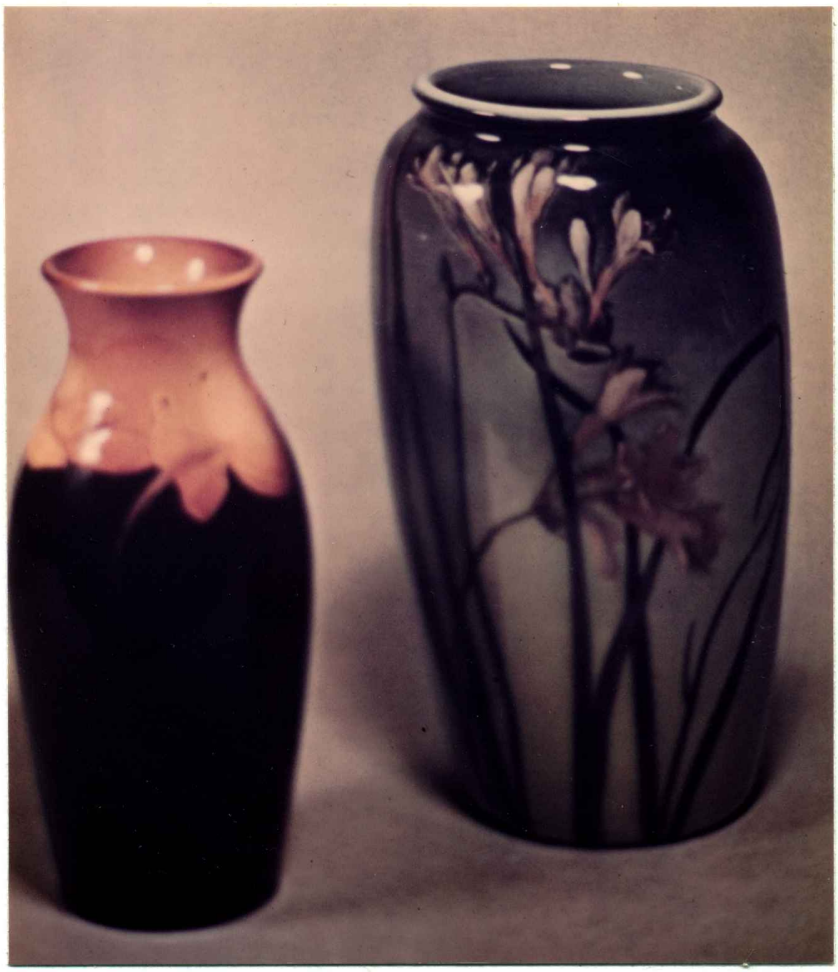

Figure 9. Rookwood Pottery Vases, 1900. Victoria and Albert Museum. 
glazed by dipping. The decorators felt they were much more artistic. Even now, there seem to be two separate schools of potters, one of a more decorative type and one which is more traditional and functional. Both are now valued for their own characteristics, and although there is still some rivalry, it seems to have lessened greatly since the $1880^{\prime} \mathrm{s}$.

By 1883 the Rookwood Pottery had developed a method of spraying underglazes on, a technique still used today. By 1885 they were using this technique on almost all their ware. With it, colors could be more subtly blended and brush strokes could be eliminated. The designs were becoming more and more subtle and refined. No longer were they decorating with grotesque animal forms. 104

Until the 1890's underglazes were being used almost exclusively in ohio. Only after that time did they start to slowly spread to other areas. From 1890 through the early 1900's the Art Nouveau style was coming into vogue. It was characterized by smaller, simpler, more refined, and swirling designs, at times combined with some relief sculptures and lusters. 105 At this same time the Arts and Crafts movement which had started in England during the 1860's was starting to be felt in the United States. It helped the public to accept new types and approaches to the decoration of pottery. There was much Oriental influence at this time, as well, which brought considerable simplicity and elegance to the work. 106

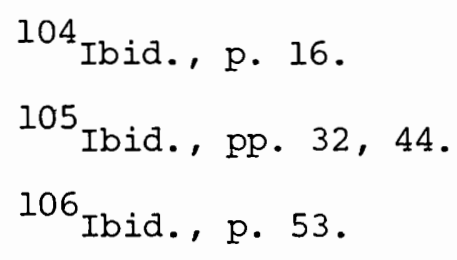


The decorations were becoming more and more illustrational, mostly to please the public. The Wellar Pottery produced "Dickens Ware", characterized by illustrations from Dicken's books. Another type used Japanese birds and Far Eastern motifs. Underglaze was also being combined with slip trailing. The Buffalo Pottery in Buffalo, New York did illustrational work which combined underglazes with decals, while the Newcomb Pottery used underglaze in combination with matt glazes instead of clear shiny glazes. 107

Because of popular demand, an art movement that had started out as a revolt against mechanically produced and repetitive objects was quickly becoming more and more like what it had sought to fight. By the time the depression was over American Art Pottery had been forgotten in an extremely industrialized society. 108

Pottery followed many new directions after 1930, but really came into its own during the 1950's. It was then that potters really started breaking away from traditional and utilitarian forms. This break was led by Peter Voulkos of the United States. His work was primarily sculptural. At first, people who wanted pottery to become one of the fine arts had almost no interest in functional forms. ${ }^{109}$ Shoji Hamada was now using engobes for his Orientally inspired designs. $^{110}$ At this time the potter had finally begun to come into

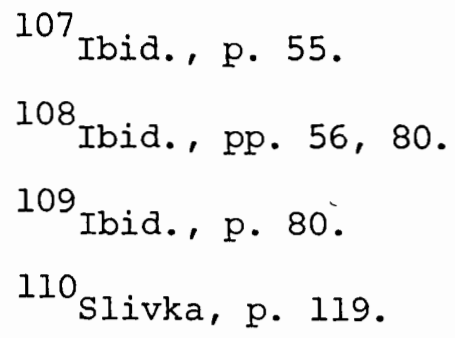


his own, his pottery was reflecting both his personality and his environment. The techniques potters were using were usually innovations on old techniques. There was an interest in brush decoration, evident in Hamada's work, but refinement was gradually being rejected and phased out. 111

Potters had always before decorated and complemented their pottery by some means. Now, contemporary artists were exploring the possibilities in not complementing a form or reinforcing a shape, trying instead to create subtle tensions between the design and the pot. They found that the effect of even the simplest of forms could be heightened greatly with decoration. Symmetry was being abandoned for both slight and drastic changes in forms. ${ }^{112}$ Their "pictures in the round" were now being used for much social commentary. ${ }^{113}$

As well as working with sculptural pieces, Voulkos also did functional work decorated with slip sgraffito, much like older Italian work, as well as Pennsylvania Dutch work. ${ }^{114}$ Rudio Autio, as was discussed under lusters, was doing large slab pieces decorated with engobes in addition to lusters. 115

Robert Arneson, a former student of Voulkos, was one of the prime instigators of Funk Art, a style popular during the 1960's, which had its origins in California. Out of funk came representationalism

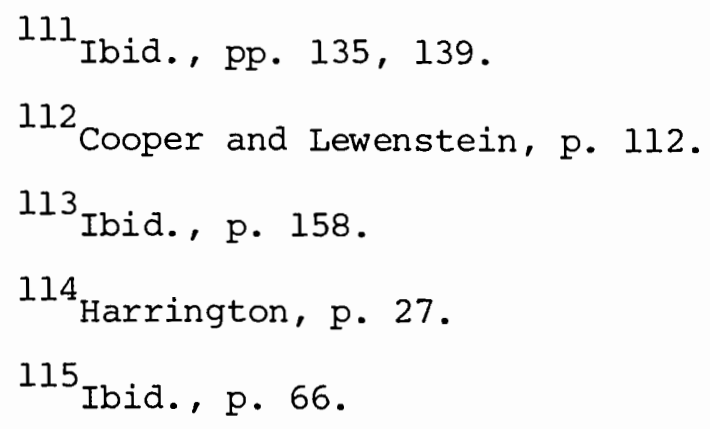


during the period around 1967. James Melchert, also from California, was one of the well known artists of this style. His rather well known Mickey Mouse plate is an example of the style. ${ }^{116}$

From 1960 until 1970 was a transitional period, a time of experimentation, with focuses on color, surface treatment, and sculptural forms. 117 From the seventies on, there has been a trend towards refinement of technique. Smoother surfaces with underglazes applied with airbrush form the background, while foreground images are added in underglaze with pencils and brushes. Often, the traditional overglaze of transparent glaze is left off intentionally. Mark Burns is one of the first to use this technique successfully. The forms are extremely refined, almost impersonal at times. One other extremely important factor in modern work is the title of the work. It is often an integral part of the work, used both to clarify and/or confuse the viewer. 118

Many ceramic artists are using underglazes now, including, Leslie McKay Johnson, whose work most often incorporates underglaze pencil drawings with slabs, ${ }^{119}$ Ed Blackburn, who does fantasy drawings on plates, ${ }^{120}$ (Fig. 10) Verne Funk, who like Johnson, uses underglaze

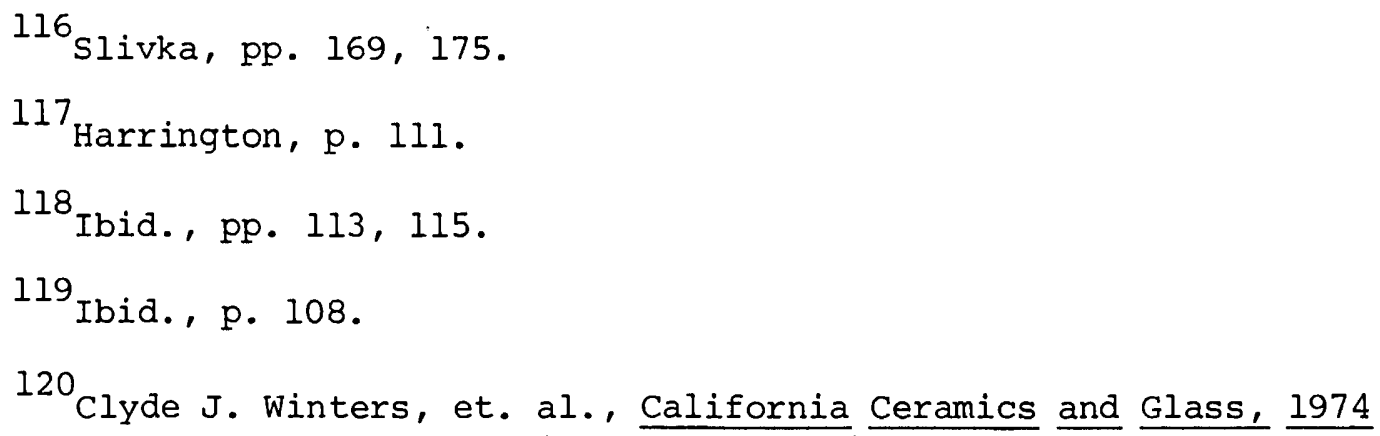
(Oakland: The Oakland Museum Design Group, 1974), pp. $29, \frac{1}{30}$. 
pencils, ${ }^{121}$ (Fig. 11) and Ken Little, who uses underglazes, glazes, lusters, and overglazes in combination with each other to tell narrative, fictional stories. Most recently he has been working on a plate format, which he sometimes partially encloses in shipping crates. 122

Others working with underglazes are David Tell, who uses them with a clear glaze cover on huge bisqued slabs which function as canvases for his abstract paintings, ${ }^{123}$ Alison Britton, whose work done on handbuilt forms, usually pitchers, has a free, almost childish style, ${ }^{124}$ and Jenny Lind, who uses oxides, underglaze pencils and chalks to create shaded drawings of both animals and humans. 125

All of the aforementioned artists use underglazes with beautiful results in ways adapted to fit their own personal styles, but one artist, Patti Warashina, is recognized as the master of this technique. She is extremely concerned with the surface of pottery. Her love of drawing and color is extremely evident in her underglaze work. Her more recent work uses satin matt glazes instead of glossy ones, as well as having much subtler colors than her earlier pieces. Her subtle use of fantastical imagery and color, as well as her superb technical

\section{${ }^{121}$ Cooper and Lewenstein, p. 162.}

122 Zena Holst, "Crate Plates", Ceramics Monthly, March, 1973, pp. 23,24 .

\section{Janice Gould, "Ceramic Paintings", Ceramics Monthly,} February, 1975, pp. 32, 33.

${ }^{124}$ Elizabeth Fritsch, "Juggling Into Jugs", American Crafts, November/December, 1979, pp. 26-31. pp. 5-10.

125 Jenny Lind, "Glaze Painting", Studio Potter, Vol. 5, No. 2, 


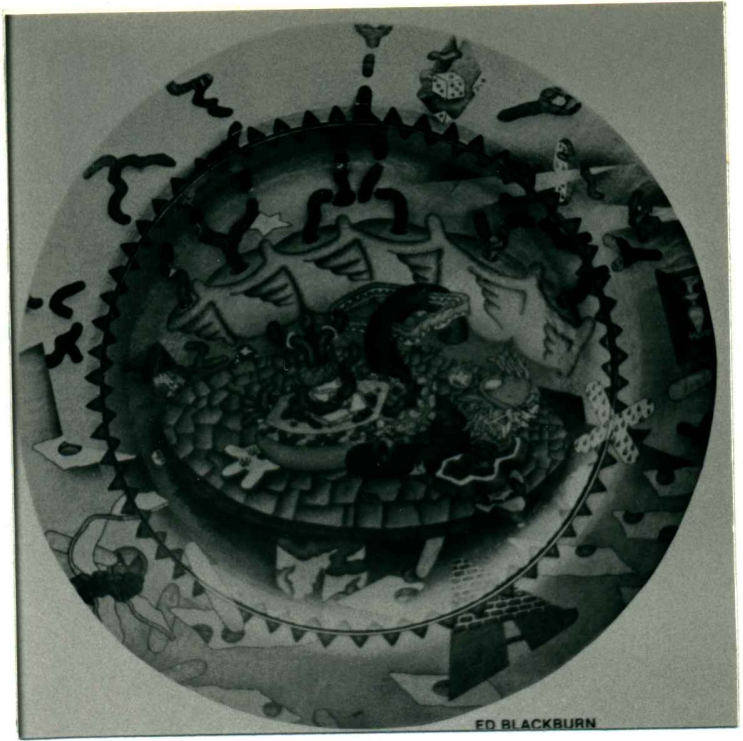

Figure 10. "The Other Side of the Coin", 1974. Ed Blackburn. The Oakland Museum.

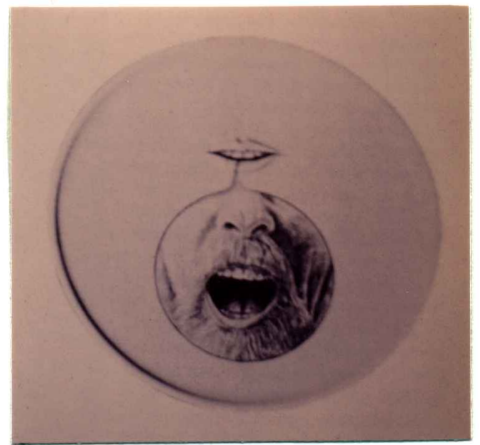

Figure 1l. "Funk Plate", 1972. Verne Funk. The Oakland Museum. 
mastery of the underglaze techniques all help complement and enhance her work beautifully. 126

More and more potters are experimenting with underglaze and luster techniques. Most of the current work is satirical, often poking fun at the techniques themselves. There is a growing appreciation for both their worth and the diverse possibilities for their use in decorating pottery surfaces. 127

\section{VARIOUS UNDERGLAZE APPLICATION METHODS}

Engobes are solutions formed from colored clays and water which have been screened to remove any lumps. They are usually the consistency of cream. ${ }^{128}$

Most engobes are applied by pouring, painting, or, dripping them onto the surface of leather hard clay, although, if the formula is altered to prevent so much shrinkage, it may also be used on bisque ware. 129 (see appendix for formulas) Engobes are almost always opaque, unless they are applied. very thinly or the solution is thinned down. 130

Underglazes are usually applied to bisqued ware which has a very smooth surface, seldom to greenware. They are composed of calcined

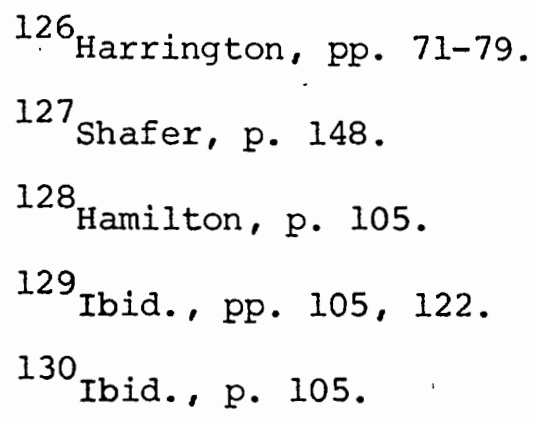


coloring agents, usually oxides, which are ground extremely finely, a refractory material, like flint, to prevent running and blurring under the glaze, and a medium mixed with a little water to improve the brushing qualities. 131

It is possible to make your own underglazes, but as with the lusters, commercially prepared ones are much more consistent and reliable. (see formulas in appendix) As well as coming in powdered form which must be mixed to a thin paste, underglazes also come in more convenient forms, pencils, chalks, watercolor-like cakes, and tempera-like paints. All the different types give results comparable to their counterpart in ordinary drawing and painting materials. The powdered colors are the strongest, with the others tending to be much paler. They may be drawn, painted or airbrushed onto the pot's surface. If a brush is used, often the brush strokes are left for greater depth. The colors may be overlapped, but the combination does not always follow "traditional" color mixing rules. Underglazes should be applied thinly. If applied too thickly, they will make the glaze crawl.

If a mistake is made it is difficult to remove all the color, even with water. A residue will often remain. 132 Sometimes it is possible to remove this residue (and underglaze) with an ordinary eraser. All eraser dust must be removed, or the crumbs will resist the glaze application. 133

$$
\begin{aligned}
& { }^{131_{\text {Rhodes, }}} \text {. } 255 . \\
& 132_{\text {Ibid. , pp. } 256,257} \\
& 133_{\text {Lind, p. } 6 .}
\end{aligned}
$$


It is also important to remember that the composition of a glaze may affect an underglaze's color. For example, glazes containing zinc oxides will prevent the development of pink colors and lead glazes bring out a different range of colors than alkaline ones will. It is best to dip, pour, or spray the chosen glaze over the underglazes, so as not to disturb the decoration.

Firing temperature will also affect underglazes and engobes. Low firing temperatures which have traditionally been used for underglazes will give brighter colors than high firing temperatures, which tend to subdue most colors, and which will make some disappear completely, especially reds and yellows. Blues are stable at all temperatures, as are most browns and blacks. In some cases reduction may also cause an underglaze to change color, and prevent some from developing. ${ }^{134}$ Different types of glazes also give different results. Satin matts will subdue colors, while glossy glazes will highlight and heighten the colors. The use of a light colored clay body works the best, allowing colors to show up well.

Some methods of underglaze and engobe application have already been discussed, but there are other, more specialized methods which deserve attention as well.

As well as airbrushing, underglazes may also be silkscreened and photo-silkscreened onto pottery. The airbrushing gives a very subtle, soft effect. The screening processes give effects similar to decals. 135

${ }^{134}$ Rhodes, pp. 255, 257. ${ }^{135}$ Ibid. , p. 257. 
Specialized engobe application methods are as follows:

Trailing

Engobe of just the right consistency (about the consistency of thick cream) is pushed out of a container with a small nozzle or tip, like a syringe or trailer, and trailed onto the surface forming a raised line of decoration. The consistency of the engobe is extremely important, for if it is too thick it will block the nozzle, and, if it is too thin will pour out.

\section{Marbelizing}

Cover a clay surface with a thin engobe, and while it is still wet pour different colored engobes over part of it. Swirl to marbelize it by shaking or rotating the piece.

\section{Feathering}

This process is a combination of trailing and marbelizing. The surface (flat is best) is covered with a thin layer of engobe. While this layer is still wet, trail parallel lines across the surface. Comb lines at right angles to the trailed engobe while they are still wet with a thin tool.

\section{Encaustic}

This technique is usually used on tiles. A form is made with recesses which are filled in with engobes. When the engobes are at least leatherhard, the surface is scraped smooth to reveal the edges of the original clay surfaces and to show the engobe-filled recesses. 
Wax Resist

A wax resist is painted onto the clay surface in places where no engobe is wanted. Engobe is painted over the entire surface and will pull away from the waxed areas.

\section{Sgraffitto}

The form is either painted with engobe and the design scratched into it to reveal the clay surface, or the clay surface is scratched, the surface painted with engobe, and the surface smoothed away until the original clay surface shows with only the scratched design filled with engobe.

\section{Terra Sigillata}

This is a type of engobe commonly found on Roman and Greek pottery. It is usually red-brown or black in color. The engobe is made of exceptionally fine particles of clay. Only the bottom $2 / 3$ of the engobe solution is used. It is painted onto the ware, burnished, then fired, no higher then $950^{\circ} \mathrm{C}$, or the sheen starts to disappear.

\section{Stencil}

This is a form of resist. The engobe is painted, poured, or sprayed over a stencil (usually made of paper) which had been attached to the pot with a little water. The stencil is then lifted up, which will leave bare areas of clay where the stencil was. ${ }^{137}$

Usually, engobes and underglazes have a coating of glaze over 137 Hamilton, pp. 108-113. 
them, but this is not a hard and fast rule. Ware which is not glazed is done so for a purpose, as is glazed ware. Throughout history different forms of underglaze work have developed and evolved into the many forms and variations which modern potters use today. 
CHAPTER II

\author{
ESTABLISHING AN APPROACH TO THE DESIGN \\ OF THE INSTRUCTIONAL UNIT
}

Bernard Leach says, "Technique is a means to an end. It is no end in itself. In our times technique, the means to an end, has become an end in itself."138

In order to discourage frustration and to encourage interest, participation, and exploration in a secondary student, he or she needs to experience a reasonable amount of success in learning a technique and to then use the technique as a means to an end, to create a product which he or she values.

During the learning process, opportunities for individual investigation within boundaries of a unit need to be allowed for, but there needs to be enough structure, especially when working with materials such as lusters and underglazes which are both expensive and somewhat difficult to apply, to assure that students don't become frustrated with the process and fail or waste the materials. The unit needs to provide for instruction in the processes as well as opportunities for mastery of the technical skills.

The quickest way to lose a student's initial interest and excitement in anything is for him or her to fail. The teacher needs to be aware of this and to create assignments which, while teaching

${ }^{138}$ John Murray, Work of the Modern Potter in England (London: John Murray Publishers, Ltd. , 1952), pp. $5 \overline{9,89 .}$ 
needed techniques and allowing for individual exploration of the technique's potential also stay within the student's capabilities and present skill level. This means at times one will have to individualize, making the assignment more challenging for quicker students, as well as making it less difficult for the slower student. A teacher must remain flexible in order to assure the success of all one's students, not just some.

Several other factors also influenced the design of this unit. Students tend to lose interest when too many examples are shown at the commencement of a unit. Prefacing examples should be minimal, selected, and the showing timed with great care. An assortment of slides and examples of actual work works best for keeping the interest level high.

students sometimes have difficulty in deciding upon imagery for their work. To facilitate their decisions, guidelines may be placed upon the types they choose. Again, individualization is a must. If a student has a good idea, which falls outside of the guidelines, it is usually preferable, if the idea is plausible, to encourage them. Only if the idea seems totally unworkable should a student be redirected. If adjustments or alterations are necessary, they should usually be minor. One should use one's own judgement in determining what should be done in each individual instance.

The purpose of this unit is not only to introduce the student to the ceramic decorating techniques of lusters and underglazes, but to give him or her time for adequate exploration and technical mastery so he or she will be able to use the techniques to produce aesthetically 
pleasing decorations which enhance the surfaces upon which they are placed.

The five projects designed to enable the students to accomplish these goals are as follows:

\section{PROJECT ONE}

Practicing techniques, as well as gaining skill and confidence in the use of underglazes are the objectives of project one. In this project the students will be working on a practice ceramic tile. The format will allow for immediate participation and for immediacy of results to keep the high interest level. The introduction of underglazes and their technical use would be taught during this project. These techniques would be more fully explored during projects two and five. Limitations could be placed on this project by pre-determining the size of the tile and the type of imagery or decoration used. These limitations would not restrict a student, but would instead limit the assignment to a manageable size for a first project with the materials.

\section{PROJECT TWO}

The second project's objective would be to allow for more practice and experimentation in the uses and potential of underglazes. The creation and application of aesthetically pleasing decoration to three dimensional surfaces would be stressed. Special attention would need to be paid to the creation and application of decorations which would become an integral and important part of the pot's form. Limitations could be made on this assignment without greatly restricting 
a student, by setting minimum and maximum sizes for the pots, and by deciding on a broad category under which the imagery and decoration would fall.

\section{PROJECT THREE}

Project three would involve the students gaining a mastery of the techniques of luster application. Techniques of application would be stressed. These techniques would be explored more fully in projects four and five. Students would create a simple striped design on a tile format. Limitations could include what colors could be used and the tile size the design would be applied on.

\section{PROJECT FOUR}

This project would allow for more practice with the luster technique. The creation and application of designs which relate well to a pot's form and size would be stressed. Again limitations could be set, including minimum and maximum sizes for the pots, as well as categories for the imagery, such as a simple pattern.

\section{PROJECT FIVE}

Upon the completion of projects one through four, a student should have gained a good mastery of the skills which could be combined into a final piece. During project five a student would be required to design and create a successful pot complete with imagery, where the lusters and underglazes complemented each other, as well as the form, shape, and size of the pot. Again, limitations could be 
placed upon the assignment in the forms of size and imagery categories.

The objectives to be achieved upon the completion of these five projects are:

1. The student will become familiar with the techniques of underglazing and be able to demonstrate their uses correctly.

2. The student will use underglazes to successfully create and decorate a well-crafted pot with imagery that is aesthetically balanced and pleasing.

3. The student will become familiar with the techniques of luster application and be able to demonstrate their uses correctly.

4. The student will use lusters to successfully create and decorate a well-crafted pot with imagery which is aesthetically balanced and pleasing.

5. The student will be able to design and construct a wellcrafted pot whose imagery is a successful blend of underglazes and lusters, which complement not only each other, but the pot as well. This unit in advanced surface decoration techniques is designed to last for approximately five weeks. It will be presented to thirty-six students enrolled in art classes at Ridgefield High School. The students it will be presented to have all had at least one and one half years of high school art, which has included a semester of drawing and painting and a quarter of ceramics. Only two of the students have had any experience with underglazing. None have had any experience with luster application. 


\section{CHAPTER III}

\section{EQUIPMENT NECESSARY}

FOR THE PROBLEM'S SOLUTION

To present this unit successfully requires not only that the instructor be completely familiar with luster and underglaze techniques, but also that proper equipment is available. Although much of the equipment needed is typical of high school art room equipment, some is more specialized. No shortcuts or scrimping with materials may be taken in order for the ware to turn out properly. Explanations of the correct equipment and it's proper use will be found in this chapter.

\section{Work Area}

A dust free and well-ventilated work area is a must. A thorough cleaning of the work area will insure there is no dust available to cause spotting on the lusters. Because of the noxious nature of the lusters, adequate ventilation must be provided for with windows and/or fans, to maintain a clean, safe breathing atmosphere.

The work area must be large enough to contain adequate tables or desks for students to work at without being crowded. Class size will determine the actual number. The work area also needs to provide a dust free storage area for the wares prior to firing.

\section{Kilns}

All work prepared for the testing of this thesis will be fired 
in an electric kiln, although any kiln, gas or electric, in good working order may be used. If in doubt about a kiln's condition, it is a good idea to have it properly inspected by a trained technician before using it. The kiln must be able to reach a temperature of at least cone 06 . All luster firing is done in oxidation. Glaze firings may be done in oxidation or reduction. For the testing of this thesis firing will be done in an oxidation atmosphere.

Kiln furniture and supplies need to include shelves and posts for stacking multiple layers of ware in the kiln and cones to insure proper shut off of the kiln. Work done by the students for this thesis will use cone 08 for bisque, cone 06 for glazing, and cone 018 for the luster fire. Different cones for glazing would be used if higher temperature glazes were used.

A very well ventilated area is necessary if the kiln will be fired in the classroom, since the luster fumes are noxious. If the kiln is outdoors or in a different room apart from classrooms, adequate ventilation needs to be provided, although it is not quite as critical.

$\underline{\text { Clay }}$

Clay must be light colored. When firing at low temperatures white earthenware, which is what will be used for testing this thesis, works the best, although light colored stoneware is an acceptable substitute if no earthenware is available. If one chooses to work at temperatures above cone 06 , porcelain is the best, followed again by a light-colored stoneware. 
Work produced as a direct result of this thesis will use a glossy transparent cone 06 lead-free glaze. Other light colored, glossy or satin matt glazes are acceptable, but will not give the same clear results. If one wishes to use higher fired glazes, the glaze will work best if it is clear. Both low and high fired glazes need to have melting points which are above cone 018, or there will be pitting, bubbling and blistering during the luster firing which cannot be corrected. If unsure how the chosen glaze will react, it is wise to test a small piece first, rather than ruin an actual finished piece. Dipping, pouring (which we will use), or spraying are the best methods of glazing to use if underglazes are present, so they will not smudge.

\section{Underglazes and Related Tools}

Commercial underglazes come in many different forms: pencils, chalks, powders, watercolor-like palettes, and liquids. The powders mixed into liquid form give the deepest and most opaque colors. They are the best choice to use, because as well as being opaque, they may also be thinned down to a transparent watercolor consistency. The underglazes already in liquid form give fairly opaque results, but the rest are weak and pale. The pencil and chalks will produce beautiful line qualities. By using different types of underglazes in combination with each other an artist can create countless different effects. The students will use chalks, pencils, and powdered underglazes singularly and in combination with each other for work done as a result of this thesis. 
These underglazes must be applied to smooth, clean, and bisqued surfaces. The pencils and chalks are applied by drawing on the surface. Water may be used to flood and bleed areas if desired. The other types of underglazes are traditionally painted on, but may also be sprayed or airbrushed on. In applying these types of underglazes the students will draw or paint them on.

Powdered underglazes are mixed with a purchased painting medium and a little water to obtain the consistency of cream. For more transparent results a little more water is added. It is best to mix these colors on a white plate or palette so the colors may be seen before application to the pot. Good quality sable or camel hair brushes are used for this application. The materials are water soluble, so all equipment may be cleaned up with water.

It is a good idea for beginners to first lightly sketch their ideas onto the surface with a pencil before applying the underglaze. If a mistake in application is made water will usually remove most of the underglaze, although sometimes a residue will remain. An ordinary eraser should take off the rest. It is important to remove all eraser crumbs afterwards to assure the glaze will attach. 139 Care must be taken to apply a thin, even coat of underglaze, not over approximately $1 / 16$ th inch thick or the glaze will crawl. After the underglaze decoration is completed, a coat of glaze, if desired, is applied by dipping, pouring, or spraying. The ware is then ready for firing.

$$
{ }^{139} \text { Lind, p. } 6 .
$$


Lusters and Related Equipment

Neither the lusters, nor their cleaner should be used or stored near flames or hot kilns, because of their extreme flammability.

Two types of commercially prepared lusters will be used by the students. One is a luster pen, similar to an ordinary felt tip pen. The luster flows out upon writing. They are extremely good for writing, detail work, and small areas of decoration. The other type is a liquid which is painted on with camel or sable brushes.

The ware to be lustered should have a clean, dry, glaze fired surface. It is best, especially for beginners, to mark out where they will luster, either with felt tip pens or with drafting tape pressed tightly onto the surface of the pot. After any necessary outlining is done, the pot is ready for the luster application. When using pens the design is applied by simply writing. When the painting technique is used there are three necessary steps to follow.

1. It works best if separate brushes are used for each different colored luster.

2. Brushes should only be dipped $3 / 4$ of the way up the bristles. Never should the metal ferrule be dipped into the luster as it is almost impossible to clean this part of the brush.

3. Lusters should be brushed on so that an overlap evens out. (i.e. start away from the end of the last brush mark and move back towards it to cover.) Do not just pick up painting where the color left off.

When applying lusters it is important to obtain as even a coat as possible. Too thin a coat results in dullness, too thick a one 
results in the blistering and flaking off of the luster.

If tape was used, it is removed when the lustering is completed and dry which takes between five to ten minutes. Small touchups may be made by rubbing the mistake with the corner of a piece of cardboard which has been lightly dipped in turpentine. Avoid dropping the turpentine onto the luster decoration as it will mottle the surface.

Once lustered, the ware should be moved to a warm, dust free area. It should be fired loosly stacked and well vented to cone 018 . In cleaning the brushes it is best to have three jars of turpentine that are labeled \#1, \#2, and \#3. clean the brushes first in jar \#1, then \#2, and finally \#3. The liquid in jar \#l should be disposed of when it becomes too cloudy and jar \#2 moved to \#1, jar \#3 to \#2, and a new jar made for \#3. This cleaning method should assure the brushes remain serviceable for a long time. ${ }^{140}$

If upon removal from the kiln some errors are found, ordinary liquid rust remover on a cardboard corner will, when rubbed upon the mistake, remove it. 141 Care must be taken to avoid erasing the decoration one wants to remain, however.

Again, there are no shortcuts to be taken with either of these techniques. $\sim$ Both the safety precautions and correct use of the materials need to be stressed with the students. The use of high quality materials offers a greater assurance of success, as does taking great care in the design and application of the lusters.

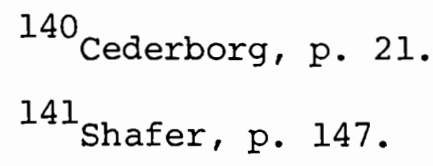




\section{ASSIGNMENTS AND TEACHING METHODS}

Prior to the presentation of the unit, students were instructed to make $k_{2}$ " thick white earthenware tiles in the following sizes and quantities: two 6" squares, one 3" square, and three 2" squares. Patterns were provided to assure uniformity. The students were shown how to smooth the tops with a rubber kidney rib and the edges with their fingers. These tiles were rolled out on burlap to make a surface that would adhere easily to a board with the proper glue.

These tiles were made earlier so that when the unit was presented, the tiles would be bisqued and ready on which to work.

\section{ASSIGNMENT ONE}

The first assigned project, figs. 12-16, was to design and create underglaze imagery that commemorated or documented an event, person, place, or thing. This imagery would be placed on a 6" tile.

When presenting this assignment to the students the techniques of applying and cleaning up the underglazes were discussed and demonstrated, as well as the importance of using good basic design in creating their tile imagery. A history of underglaze and its uses was also presented at this time. Examples of underglaze work by the author were shown and the objectives of the assignment discussed. 
desiqns on paper first, have them checked by the instructor, then to apply the underglaze imagery to their tiles. The creation and application of imaqery took two and one half class periods. During the last half of the third class period, students were shown how to glaze their tiles with the dipping methad. They were allowed to glaze them during the remaining time. The tiles were fired the next day.

The tiles were limited in size to prevent the students from spending too much time in trying to decorate a surface too large for their skills, which would likely cause frustration and loss of interest in the unit. The first project was meant for trial and experimentation with the materials.

The students displayed a high degree of interest and motivation when they started working on their tiles and were eager to have their first efforts fired. A few had difficulty deciding on something to commemorate and chose to do scenes, instead. The results of these tiles were generally less successful than the tiles with commemorative motifs.

Most students were able to make good use of the whole tile and not just. part of it. The students who planned more carefully and took, their time with the underglaze application had more success with their tiles. As a whole the students found the underglaze adapted easily to fit each one's personal style.

When the results of this assignment were discussed the reactions were generally favorable. Most of the tiles were successful. The students themselves recognized where improvement in their work was needed and helped each other by contributing suggestions for future improvements. 


\section{ASSIGNMENT TWO}

Assignment two, figs. 17-21, was to design and construct a ceramic piece with narrative imagery done in underglaze. There was a limit of seven inches put on height, so the students wouldn't tackle a project too large for their capabilities.

The presentation of this lesson stressed the importance in considering the total piece when the imagery was designed and applied. Different ways to tell a story were discussed, as well as the objectives of the assignment. Examples of works shown were:

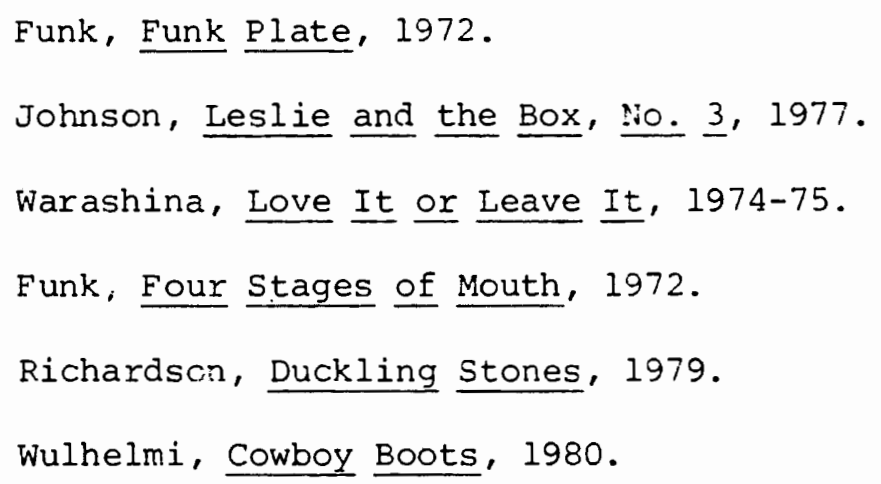
and layout. They drew out their designs on paper first, discussed them with the instructor, modified them if necessary, and constructed the ware. When their work was bisqued they underglazed it, then glazed it. It took most students several class periods to decide upon imagery and pottery forms, three class periods to construct their forms (xanging from traditional to sculptural), and an additional three class periods to apply the underglazes to the fired pottery. Many students experienced great difficulty in designing the 
imagery for their forms. A few students requested permission to luster areas of the forms made for this unit. When the lustering was added the results were more successful.

Unfortunately most students did not achieve success and were not pleased with their results. Many of the finished projects had imagery that was trite and did not become an integral or important part of the form.

\section{ASSIGNMENT THREE}

The third assignment, figs. 22-26, was to design a striped design for the $3^{\prime \prime}$ tile and apply it with lusters.

During the presentation of this assignment samples of work by the author were shown. The proper techniques of luster application, touchup, and cleanup were discussed and demonstrated. The use of lusters throughout history was presented at this time. The objectives of the assignment were also discussed. Students were reminded to keep rules of good composition and balance in mind when designing their tiles.

After the presentation students again created their designs on paper, and after discussing them with me, applied their lusters to the tiles.

Most students finished this assignment in two class periods. Their response to this assignment was generally favorable. A rise in their confidence could be seen and they approached this assignment with more enthusiasm than they had assignments one or two. Most tiles were successful. A few students drew small pictures to go along with their striped designs. These tiles were generally less successful than the 
tiles which had only been striped. The students who did pictures were reluctant to show their tiles during the discussion of the assignment. The only difficulty students experienced was in cleaning up the edges of the stripes. Several had to start over because they used too much cleaner which distorted the edges of their designs.

\section{ASSIGNMENT FOUR}

The fourth assigned project, figs. 27-31, was the design and creation of a piece of pottery with a patterned luster design. A limit of five inches in height was applied to this assignment to aid the students in the application of their lusters as well as assuring that the small amount of luster available would accomodate all student's needs. During this presentation the objectives for the assignment were discussed. Examples shown were:

$$
\begin{aligned}
& \text { Hum, Covered Jar, } 1980 . \\
& \text { Warashina, Car Kiln, } 1972 . \\
& \text { Yanagihara, Flower Vase, } 1971 . \\
& \text { Cooper, Covered Jar, } 1926 .
\end{aligned}
$$

Again, basic design skills and the importance of designing in relation to the whole piece were stressed.

Following the presentation students created their design on paper and after discussing it with me, constructed the pot which took approximately four class periods. The form was bisqued and glaze fired, the lusters were applied. The luster application took three class periods.

Students approached this assignment with a fair amount of 
enthusiasm. They did a better job designing the total surface of their forms for this assignment than they had for assignment two. Some students chose to do flat work, such as plates, which worked well. Many were able to eliminate the need for luster touchup after firing by applying the lusters more carefully.

When this assignment was discussed the responses were favorable. The students as well as the author were pleased with the results.

\section{ASSIGNMENT FIVE}

The fifth assignment, figs. 32-36, was to design imagery for the last 6" tile. The subject matter was to center around wildlife and vegetation of the Pacific Northwest. This tile would combine the use of luster and underglaze. All the tiles the students made will be mounted on a plaque to be donated to the high school. It will be hung in the main office.

In presenting this lesson, the objective for the project were discussed, as well as the importance of creating an image that made good use of the whole tile. The use of the lusters and underglazes to complement each other was also discussed. Byzantine and Delft tiles as well as works by Antonio Gaudi were shown.

After designing their tiles and having them approved, the students applied the underglaze, glaze, and luster to their tiles. In addition to the 6" tiles each student also glazed their three 2" tiles with clear glaze to serve as a border for the finished plaque. Student interest for this assignment was generally high. Most were excited and pleased to be able to make something which would be 
permanently displayed in the school. They planned much more carefully for this assignment than they had for assignment one. They also took more time to complete this tile. It took most students four class periods to design, modify, and create the underglaze imagery on their tiles and another class period to luster them. In some instances the addition of luster was not necessary.

There were more successful results from this assignment than there had been from the other assignments. Students exhibited good design skills in the creation and application of their imagery to the tiles. The success of these tiles can also be attributed to the technical mastery of the materials by the students and their desire to leave only good work to become part of the permanent display for the school. 


\section{CHAPTER V}

\section{EVALUATION AND RECOMMENDATIONS}

The introduction of luster and underglaze techniques into the author's ceramics curriculum proved to be quite successful. The major difficulty encountered was making certain that students not participating in the surface decoration unit received a sufficient amount of the instructor's time. The response from the students was generally favorable. Many asked to continue the work next year. Quite a few students not involved in the project expressed interest in being able to use lusters and underglazes during the following year. Four students inquired about purchasing their own materials for continued use outside the school. Most students involved wanted to take their work from these assignments home, which is unusual, because frequently many students place little or no value on the projects they complete for school related assignments. These positive responses lead the author to believe that incorporation of lusters and underglazes into the secondary ceramics curriculum would evoke high interest and would also expose students to a wide variety of experiences both in basic design and ceramic design. The time spent waiting for pots to be bisqued was constructively used by most students to complete projects outside the framework of the unit which they had wanted to make.

Assignment one was developed to allow students to explore the different methods in which underglazes could be applied, as well as 
gaining technical mastery of the materials. Although the assignment was designed for experimentation, limitations, such as the size of the tile format, were incorporated to facilitate the success of the students.

The students approached this assignment with enthusiasm. This being the first experience for most to use the materials was one of the contributing factors. The project being finished quickly so they could see their results shortly after completion was undoubtedly the other.

The two problems students encountered were a tendency to apply the underglaze too thickly which made the glaze crawl and the colors being used directly out of the containers which made them too intense. During future presentations the correct consistency of underglaze will be stressed. To encourage students to blend colors, the limitation of a monochrome palette could be instituted.

Although some of the results were extremely poor, student interest remained high. This was most likely due to the fact that the majority of the students had succeeded. The successful students helped the less successful ones by sharing their techniques.

Limitations on the assignment proved to be successful. Some students found it impossible to stay within the limits, but the majority stayed within the guidelines and were much more pleased with their results than were the ones who had strayed from the guidelines.

The tile format was extremely successful. The small size enabled the students to finish the project without being overwhelmed 
with the process. The two-dimensional aspect of it also contributed to its success. With it, students needed only to concentrate on the use of the materials, since two-dimensional design was not new to them. Good design elements were evident and successfully used on most tiles. Assignment two was the least successful of any of the assignments. The design of a three-dimensional surface using narrative imagery proved to be too difficult for most students. Many lost interest in the assignment and had to be prodded to finish it. Several students did not complete this assignment. Before using this assignment again it would need to be modified.

A different theme for imagery would help. A possibility could be commentary on a world or social problem or a current event. Also, the format could be changed. A plate format would be easier for the students to handle. Three-dimensional design could come later, in the fourth and fifth assignments.

Assignment three was probably the second most successful project. The students were all interested in the appearance of the lusters. In addition, the design qualities of the majority of the striped designs were extremely successful. Most students did not have the difficulties applying the lusters that was anticipated. More emphasis on preliminary luster touchup prior to firing should eliminate most of the need for touchup after the luster firing. Luster pens were easier for the students to use than the painted on lusters, but since they only come in silver and gold limitations for their use are great. Students approached assignment four with much more enthusiasm than they had assignment two. This was most likely due to the success 
they had experienced with assignment three, as well as their interest in the lusters.

Most were able to apply good basic design elements into their creation of a design for this assignment. In the future a plate format could also be incorporated into the limitations for this assignment without greatly hindering the students. This would be especially helpful if the students were having trouble with either the application methods or the creation of a design that enhanced the form.

Assignment five drew high interest from almost all the students. To be able to make an object that would be displayed permanently in the school helped the majority involved to gain in their self esteem and worth. Their underglaze and luster skills were markedly better than when they began the unit. Their confidence had also risen considerably. The design of most of the tiles was successful. The only major problem encountered during the completion of this assignment was that students wanted to luster almost their complete tile, which in some cases worked, but in most, it was necessary to redirect students.

Upon completion of the five assignments, a display of selected work was prepared by the students for viewing by the student body and faculty. It was hoped that by displaying the student work the students themselves could see the worth of their work more clearly, which would serve as a means of motivation, extrinsic and intrinsic. From the positive comments received by the students and myself the work was greatly appreciated.

When presenting this unit in the future, the modification of the assignments, as stated previously, would improve it. Another 
suggestion would be to organize a visit to a local gallery displaying luster and underglaze work prior to the implementation of the unit. This type of experience would help to motivate the students and would expose them to a broader background than could be obtained in the classroom.

When this unit was presented time was an important factor. The next time it is to be presented time should not receive as much emphasis. It would have been better to let students work at a slower pace especially during assignment two where they experienced the greatest difficulties. If the unit had been presented earlier in the school year student interest would most likely have been even higher.

The overall enthusiastic response and approach of the students to the unit, in addition to the overall quality of the majority of the results leads the author to recommend the incorporation of a surface decoration unit using lusters and underglazes into a secondary ceramic curriculum.

To present this unit successfully two recommendations should be followed.

1. The instructor should be totally familiar with the techniques involved in the use of lusters and underglazes.

2. The proper equipment and materials for underglazing and lustering should be available.

The author of this thesis will use this unit, with modifications, again. In the future, this unit wherever it is incorporated, should continue to produce many different and exciting results, each unique to the interests, abilities, backgrounds, and personal styles of the students involved. 
WORK DONE BY THE STUDENTS 


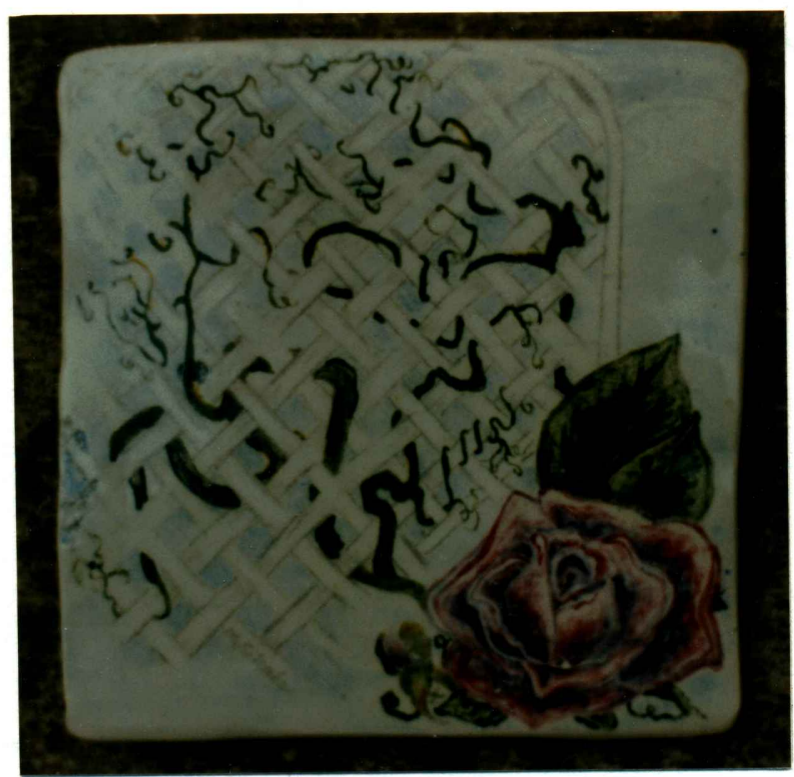

Figure 12.

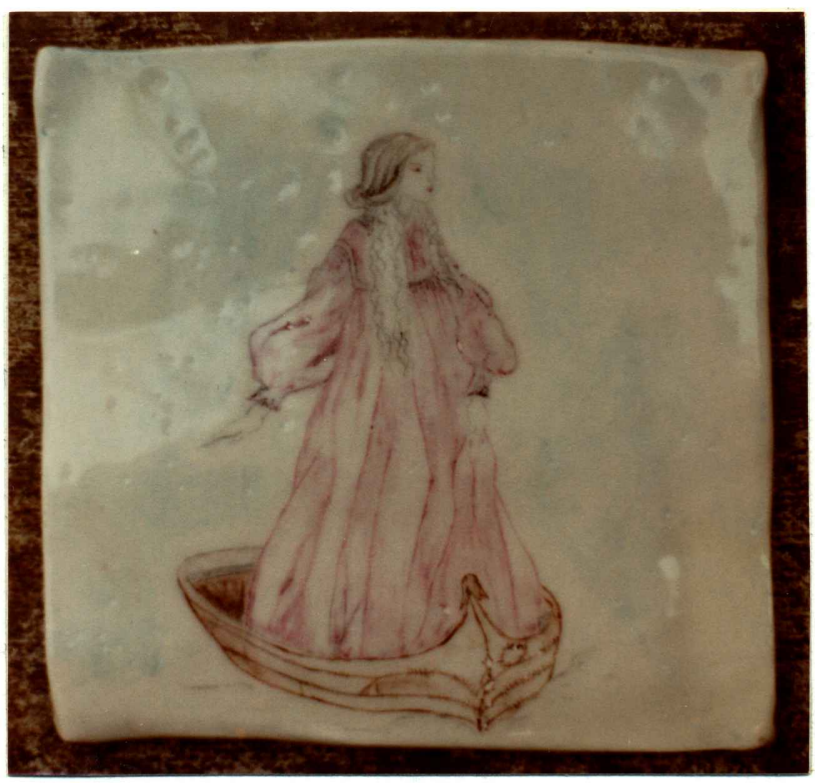

Figure 13. 


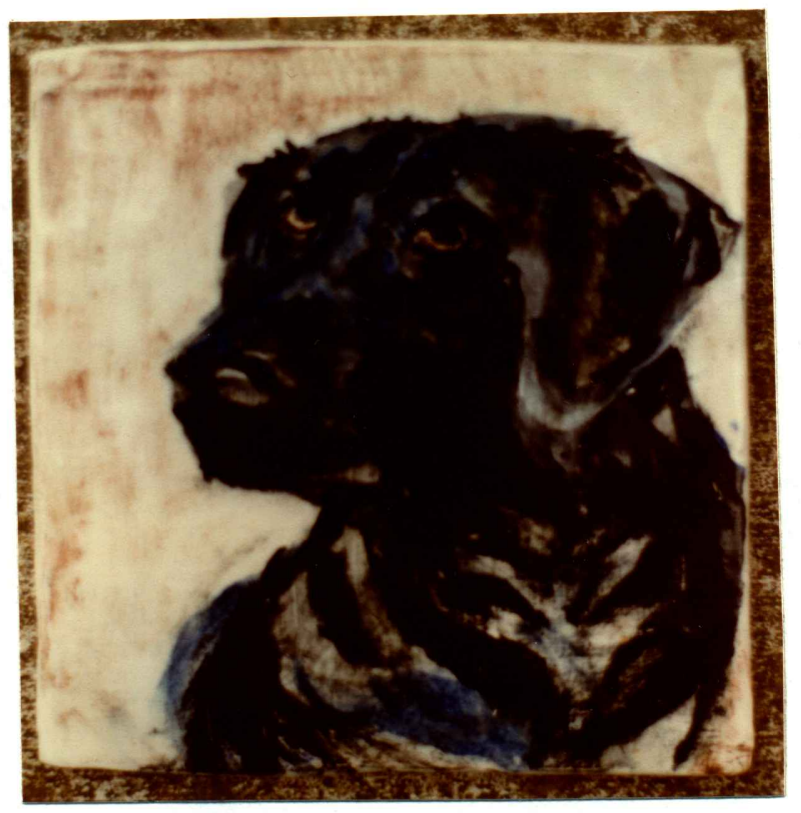

Eigure 14.

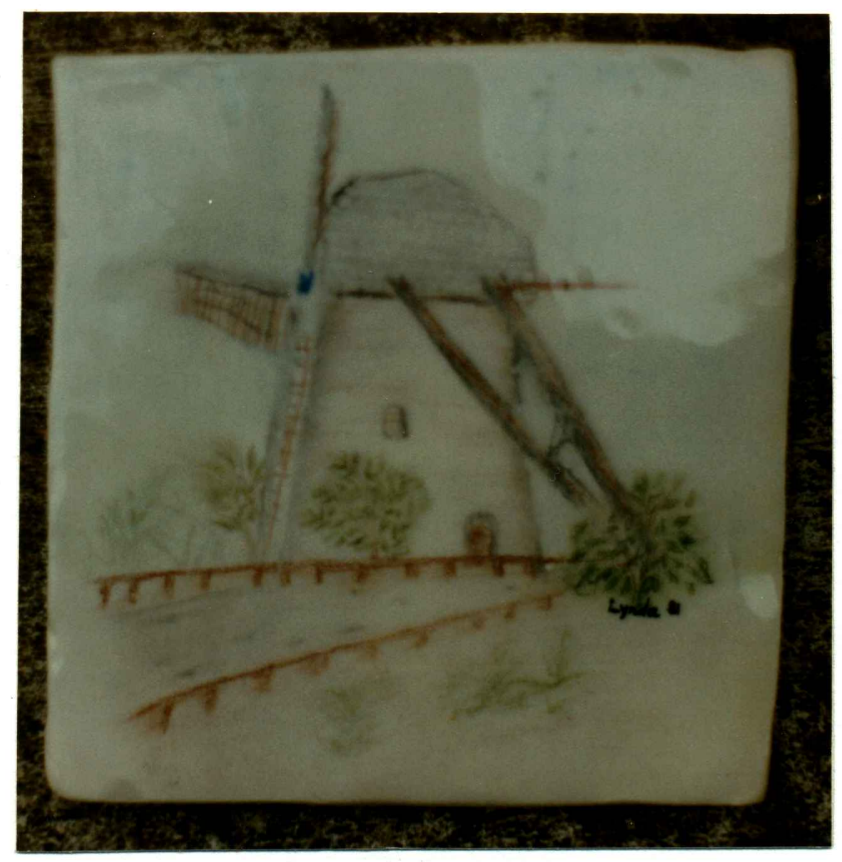

Figure 15. 


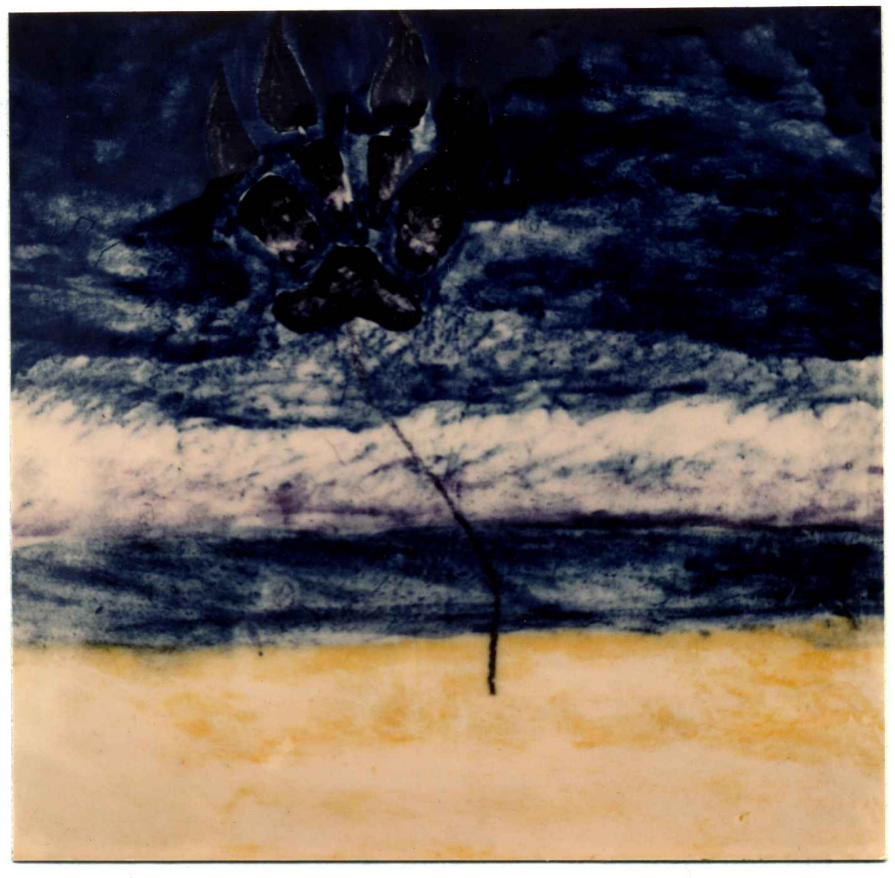

Figure 16.

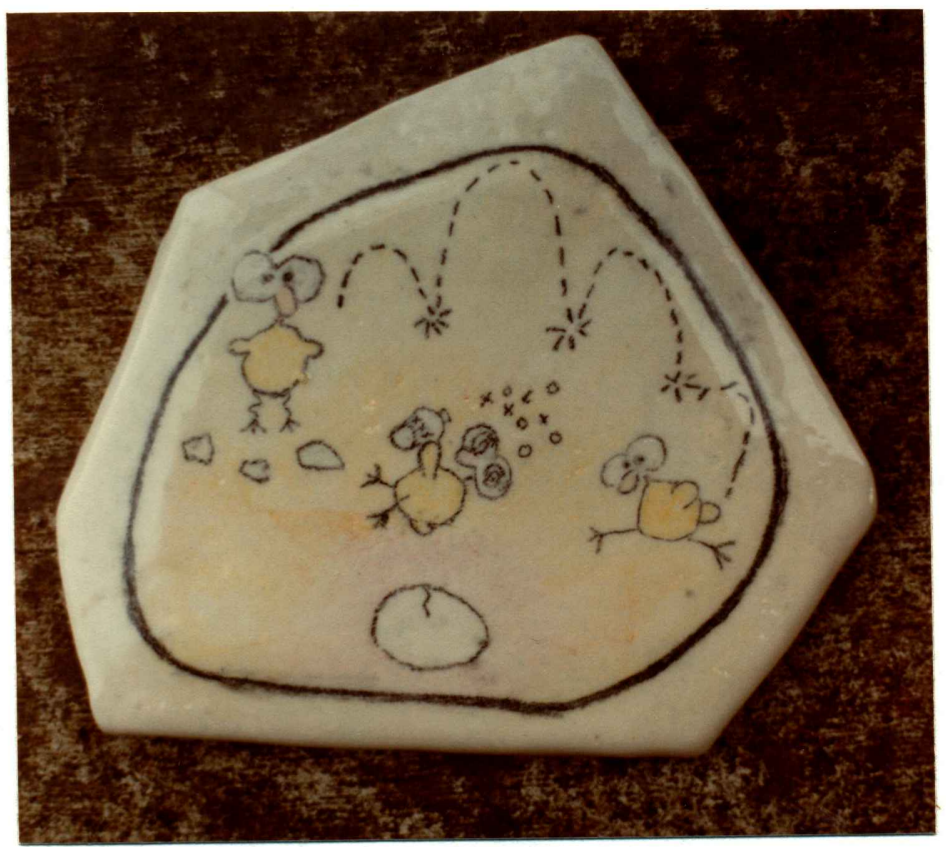

Figure 17. 


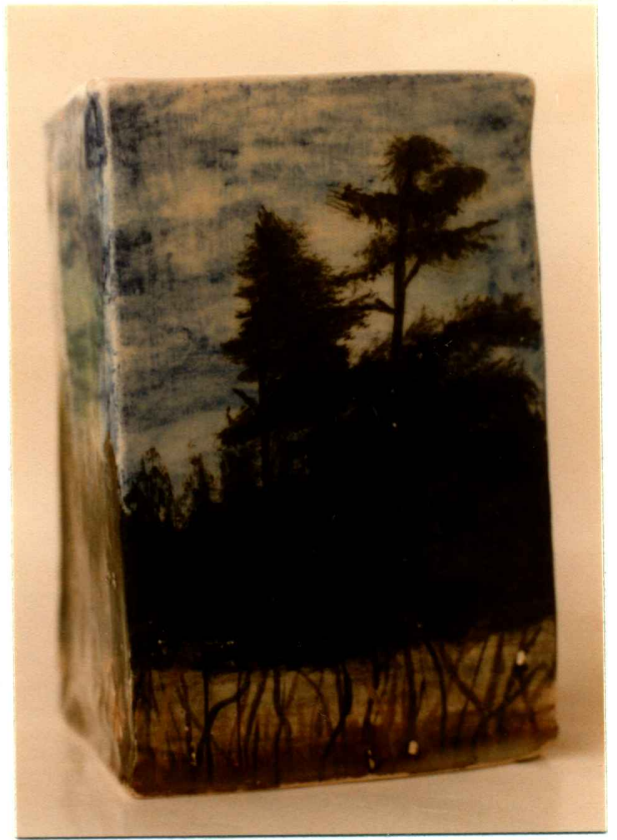

Figure 18.

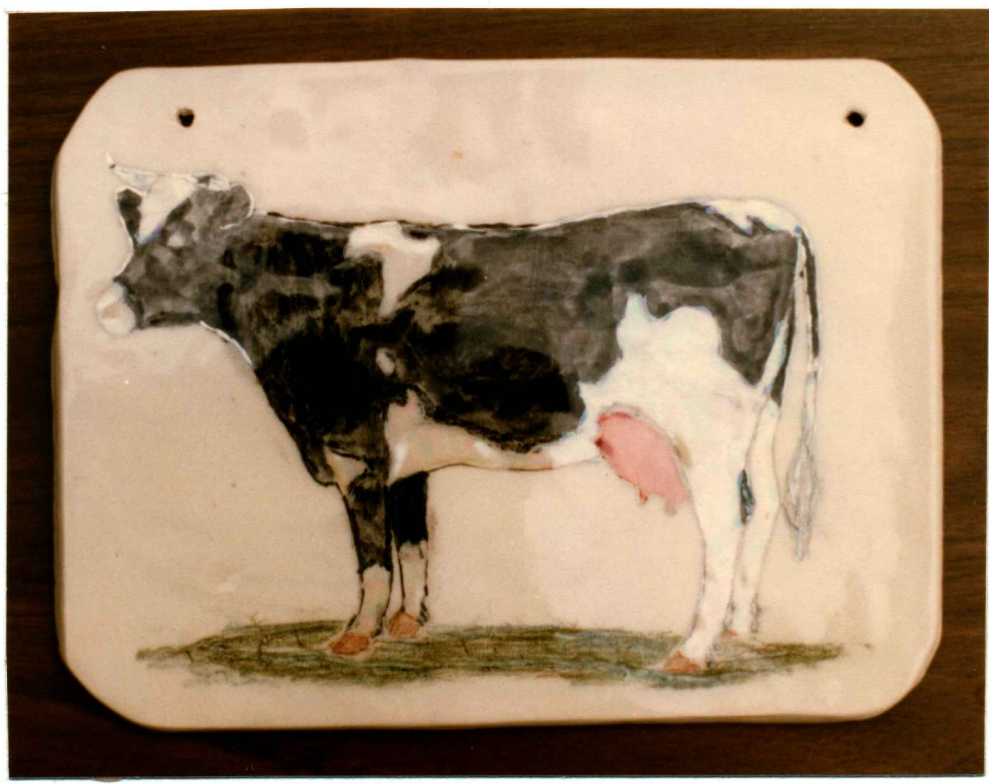

Figure 19. 


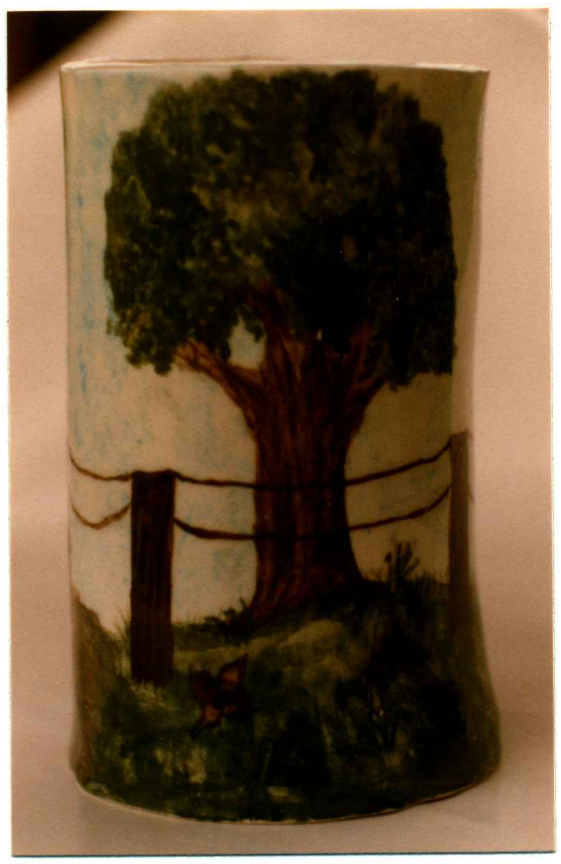

Figure 20.

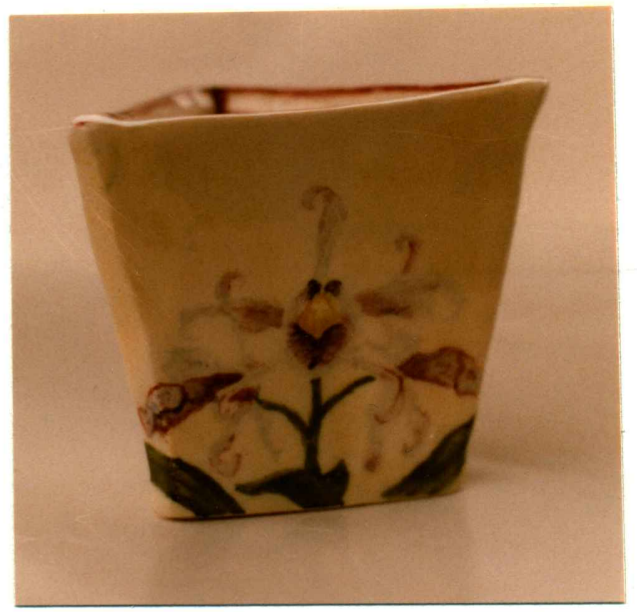

Figure 21. 


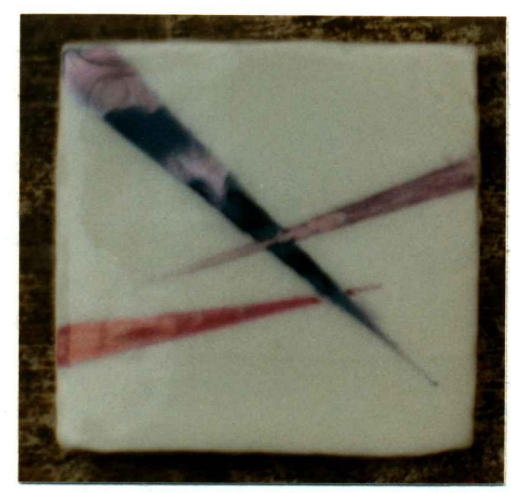

Figure 22.

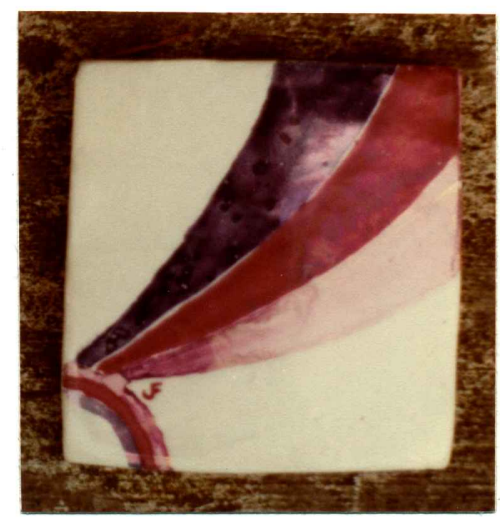

Figure 23. 


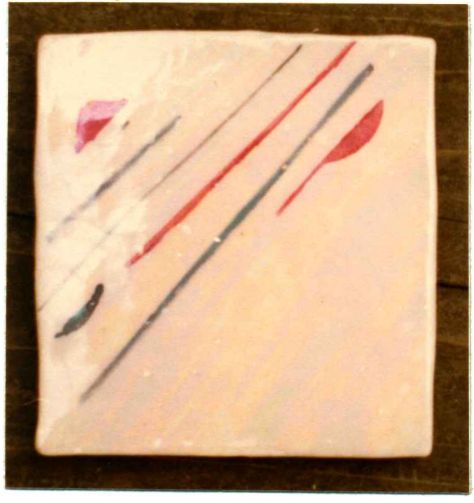

Figure 24.

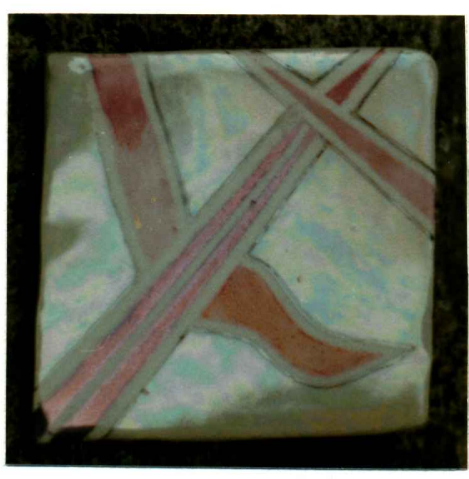

Figure 25. 


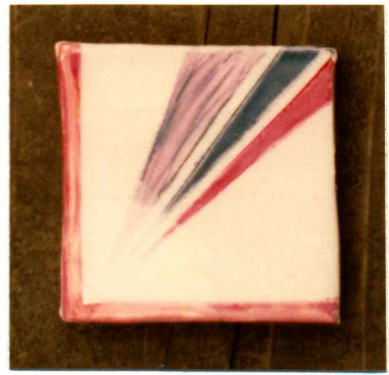

Figure 26.

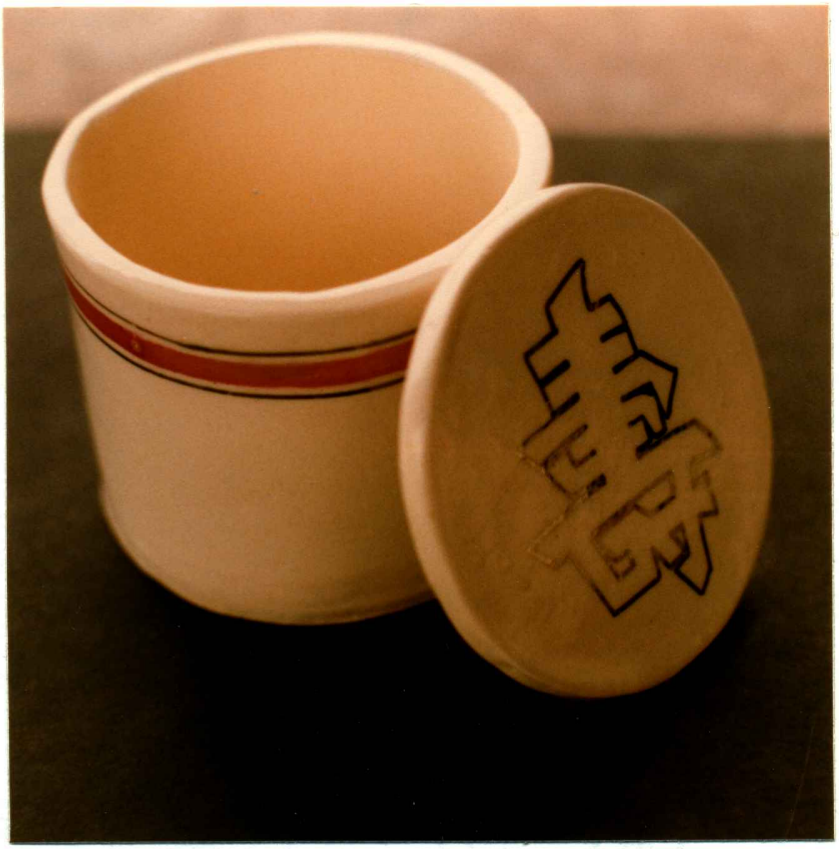

Figure 27. 


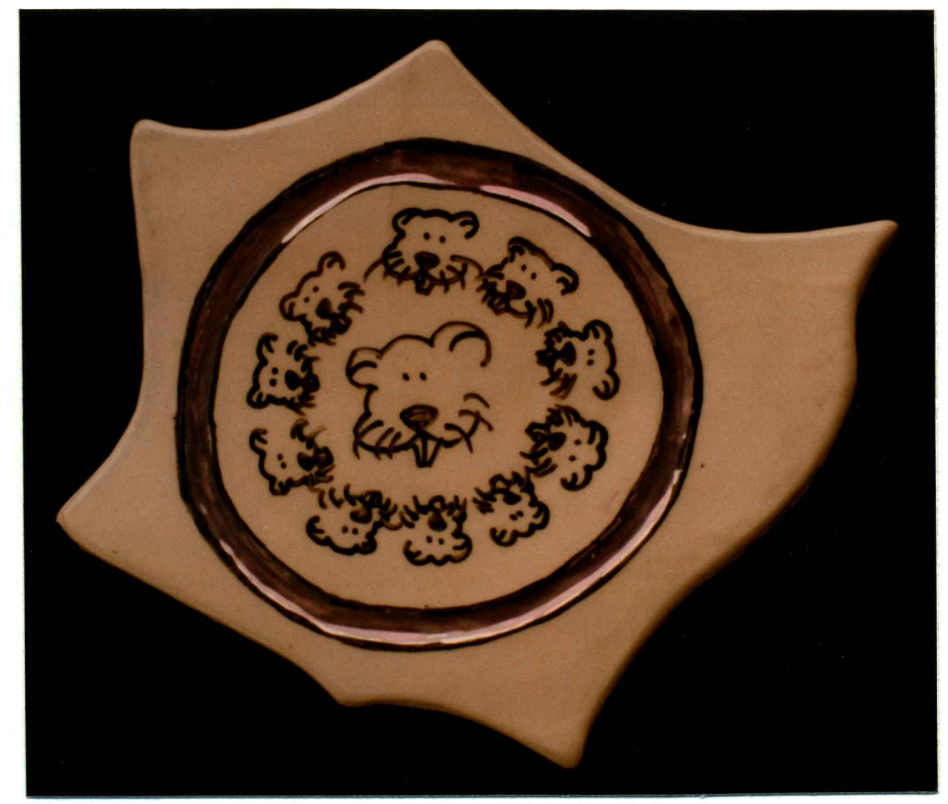

Figure 28.

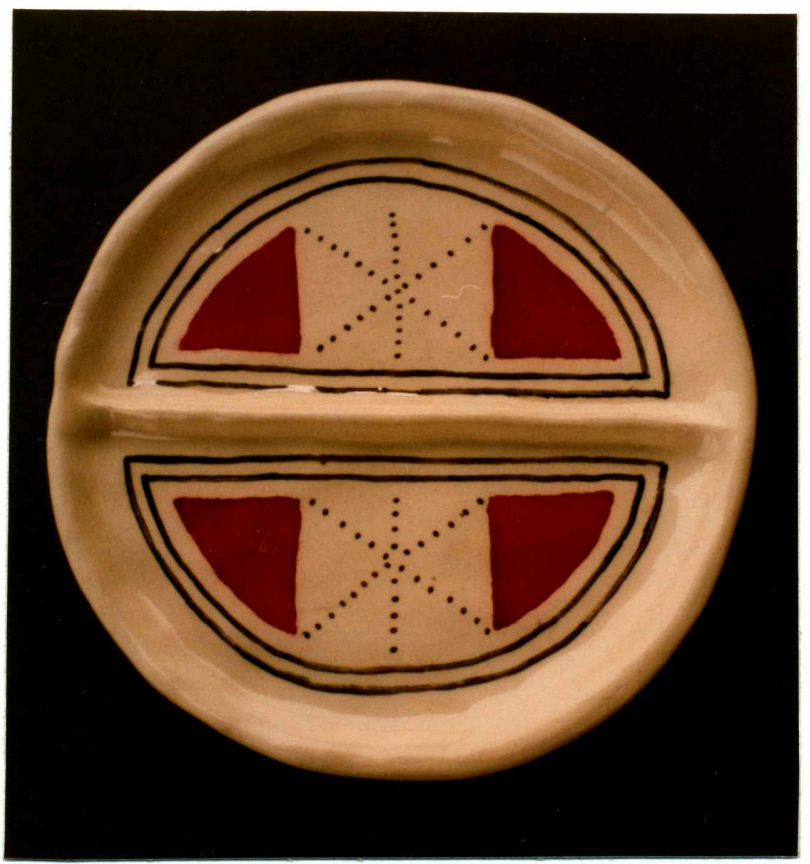

Figure 29. 


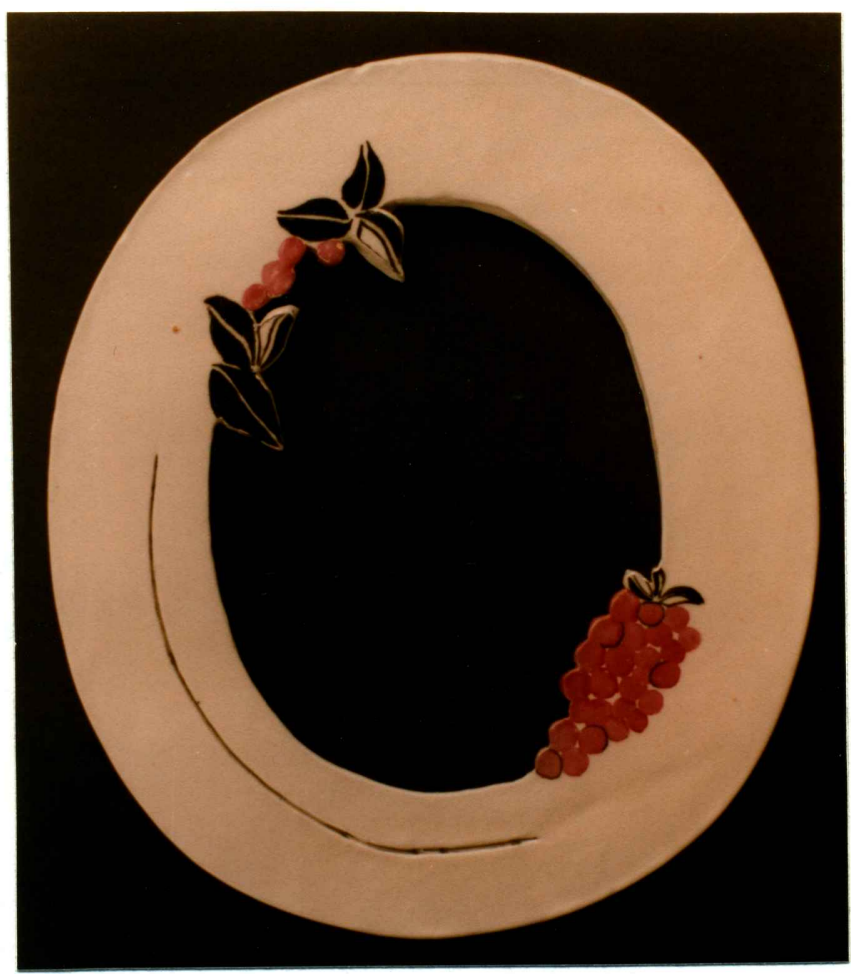

Figure 30.

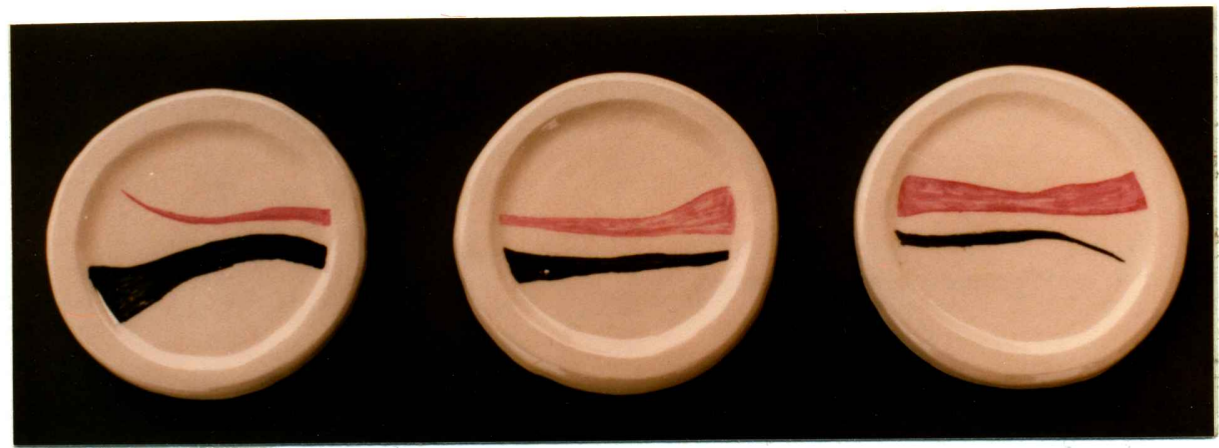

Figure 31. 


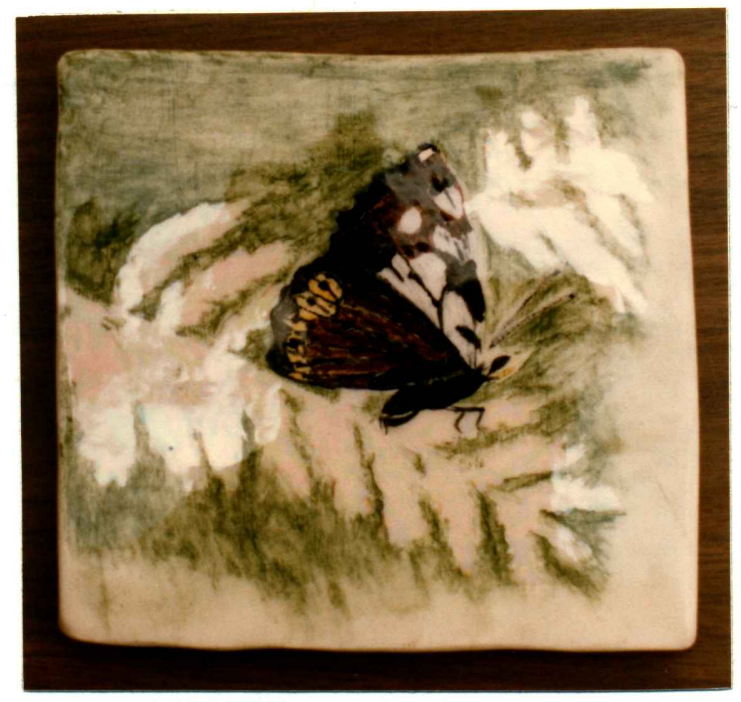

Figure 32.

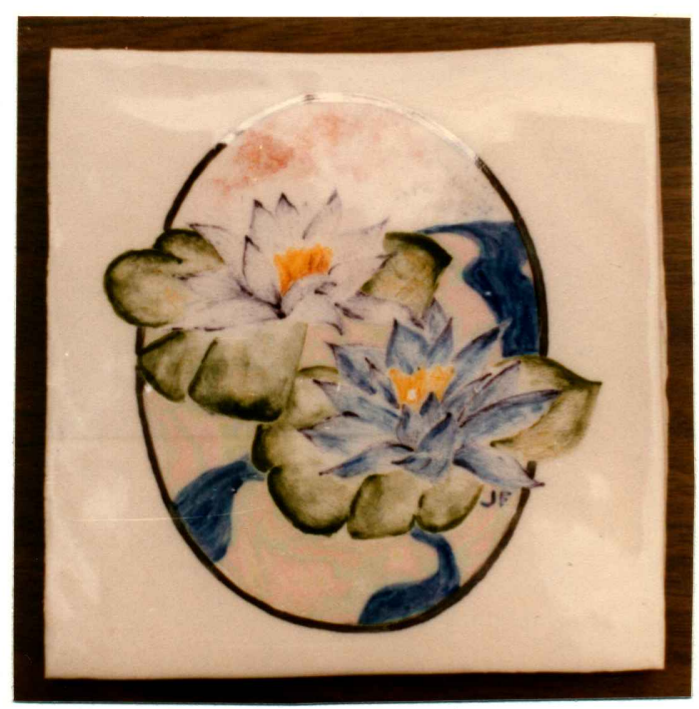

Figure 33. 


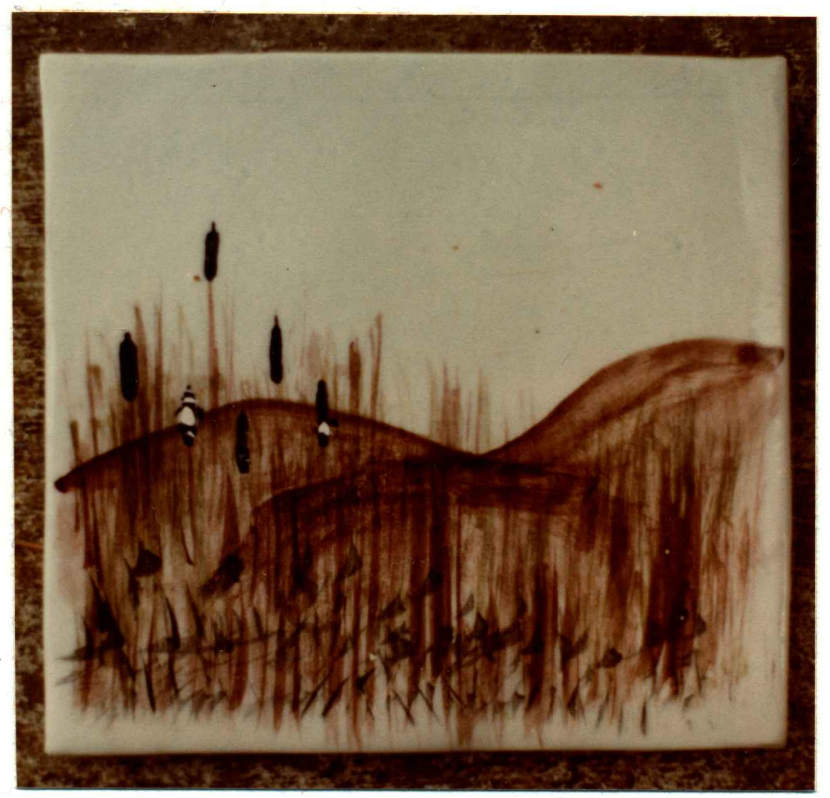

Figure 34.

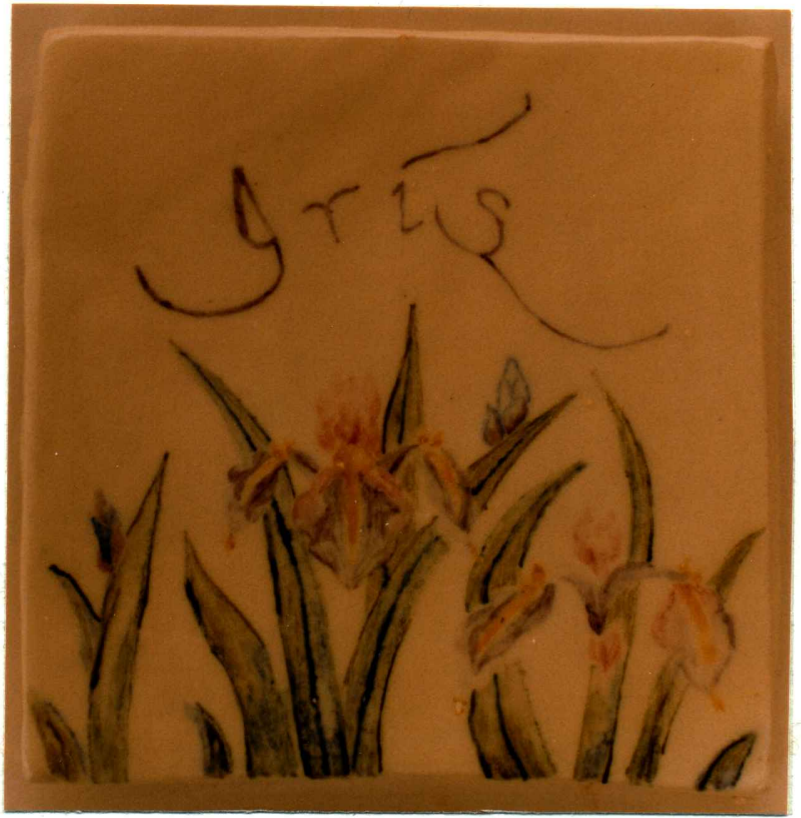

Figure 35. 


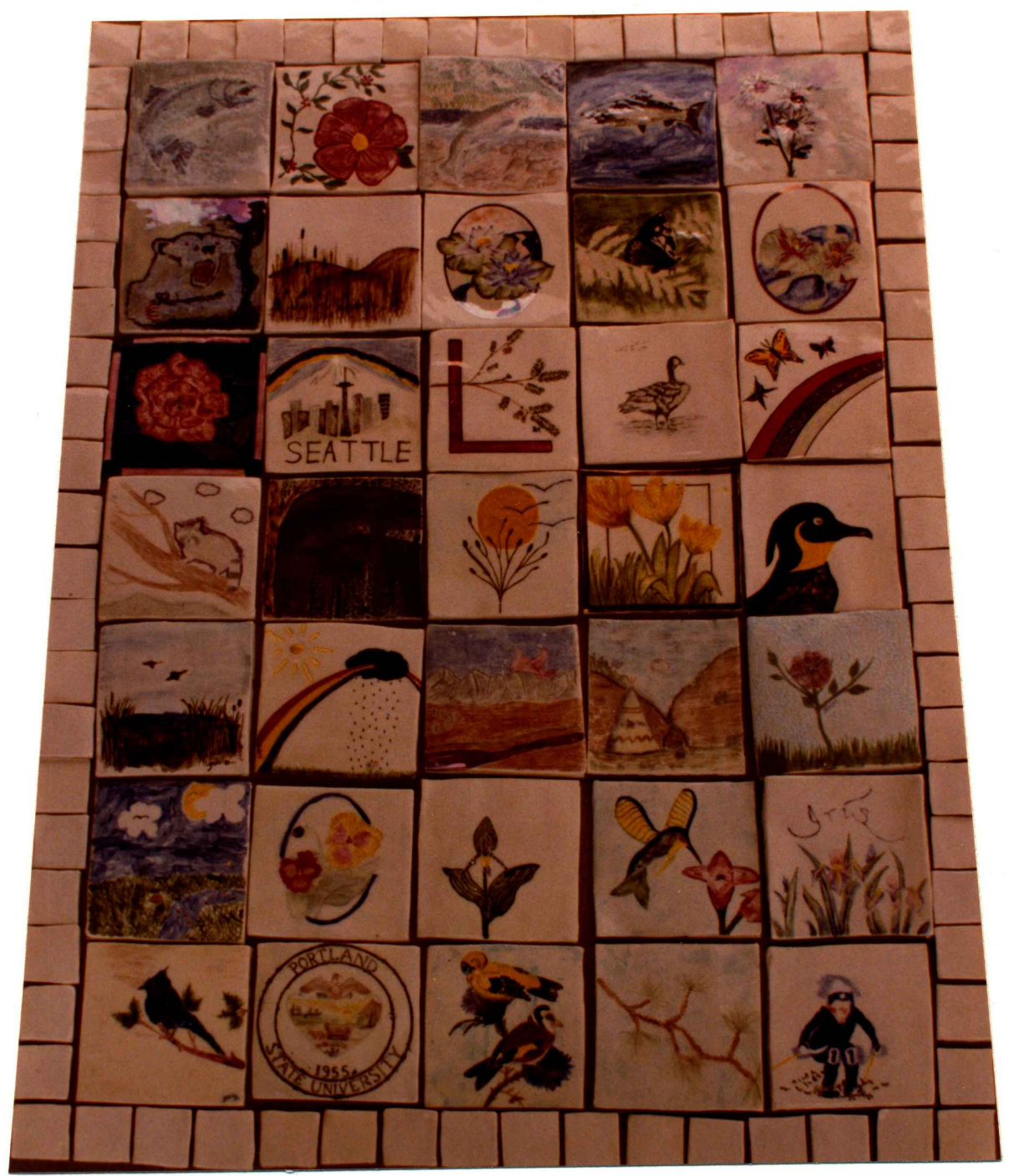

Figure 36. 
Cederborg, Nils. The Art of Luster Painting. Colombus: Nils Cederborg Associates, no date.

Conrad, John W. Contemporary Ceramic Techniques. Englewood Cliffs: Prentice Hall, Inc., 1979.

Cooper, Emmanuel and Lewenstein, Eileen, ed. New Ceramics. New York: The Van Nostrand Reinhold Company, 1974.

Cooper, Emmanuel and Royle, Derek. Glazes for the Potter. New York: Charles Scribner's Sons, 1978.

Donhauser, Paul S. History of American Ceramics: The Studio Potter. Dubuque: Kendall Hunt Publishing Company, $1 \overline{978 .}$

Fritsch, Elizabeth. "Juggling Into Jugs". American Crafts, November/ December, 1979, pp. 26-31.

Gould, Janie. "Ceramic Paintings". Ceramics Monthly, February, 1975, pp. 32-33.

Hamilton, David. Manual of Pottery and Ceramics. Toronto: Thames and Hudson, Ltd. , 1974 .

Harrington, La Mar. Ceramics in the Pacific Northwest. Seattle: University of Washington Press, 1979.

Hobson, R. L. A Guide to Islamic Pottery in the Near East. London: British Museum Publishers, 1932.

Holst, Zena. "Crate Plates". Ceramics Monthly, March, 1973, pp. 23-24.

Keen, Kirsten Hoving. American Art Pottery 1875-1930. Wilmington: Delaware Art Museum, 1978.

Lind, Jenny. "Glaze Painting". Studio Potter, vol. 5, no. 2, pp. 5-10.

Murray, John. Work of the Modern Potter in England. London: John Murray Publishers, Itd., 1952.

Nordness, Lee. Objects: USA. New York: The Viking Press, 1970.

Rhodes, Daniel. Clay and Glazes for the Potter. Philadelphia: Chilton Book Company, 1957 .

Sanders, Herbert H. Glazes for Special Effects. New York: WatsonGuptill Publications, 1974. 
Savage, George. Pottery Through the Ages. London: Cassell and Company, Ltd., 1959.

Shafer, Thomas. Pottery Decoration. New York: Watson-Guptill Publications, 1976.

Slivka, Rose, ed. The Crafts of the Modern World. New York: Bramhall House, 1968.

Winters, Clyde J., et. al. California Ceramics and Glass, 1974.

Oakland: The Oakland Museum Design Group, 1974 . 


\section{APPENDIX}

Arabian Luster Formulas ${ }^{142}$

Slight Blue Luster cone 019

Red Ochre

Bismuth subnitrate 12

Silver carbonate 3
Variable Silverish Luster cone 019

Yellow Ochre 80

Bismuth subnitrate $\quad 16$

Silver nitrate, dry

\section{4}

$\underline{\text { Flash Luster Formulas }}^{143}$

Add to either of the following base glazes 1-2\% silver nitrate, $3-4 \%$ bismuth subnitrate, or $1-2 \%$ copper sulphate.

Formula 1
$\mathrm{PbO} \quad .5$
$\mathrm{K}_{2} \mathrm{O} \quad .2$
$\mathrm{Al}_{2} \mathrm{O}_{3}$
.18
$\mathrm{SiO}_{2}$
1.5
$\mathrm{CaO} \quad .3$

Formula 2

$\mathrm{K}_{2} \mathrm{O} \quad .1$

$\mathrm{Na}_{2} \mathrm{O} \quad .6$

$\mathrm{CaO} \quad .2$

$\mathrm{ZnO} \quad \mathrm{I}$
$\mathrm{Al}_{2} \mathrm{O}_{3}$
.3 $\mathrm{B}_{2} \mathrm{O}_{3} \quad .25$

$\mathrm{SiO}_{2}$

2.5

Resinate Luster Formula ${ }^{144}$

20 pts. melted resin

5 pts. bismuth nitrate

30 pts. hot lavendar oil

Apply to fired glaze and refire to $1328-1346^{\circ} \mathrm{F}$.

142 
White Engobe Formula ${ }^{145}$

$\begin{array}{ll}\text { Ball Clay } & 50 \% \\ \text { China Clay } & 20 \% \\ \text { Feldspar } & 20 \% \\ \text { Flint } & 10 \%\end{array}$

To color this formula add:

5\% Copper Carbonate to produce green.

3\% Cobalt Carbonate to produce blue.

$\underline{\text { Underglaze Formulas }}^{146}$

Naples Yellow

Antimony Oxide 24

Red Lead 48

Tin Oxide 16

Niter

2

Brown

Iron Oxide 30

Green Chrome Oxide 28.5

Zinc Oxide
Blue

Black Cobalt Oxide 26

Zinc Oxide 104

Flint

Black

Red Iron Oxide 10

Chrome Oxide $\quad 76$

Black Cobalt Oxide 20

Manganese Dioxide $\quad 12$

${ }^{145}$ Ibid. , p. 166

${ }^{146}$ Rhodes, p. 255. 